\title{
ICTS AND JOBS: COMPLEMENTS OR SUBSTITUTES?
}

THE EFFECTS OF ICT INVESTMENT

ON LABOUR MARKET DEMAND

BY SKILLS AND BY INDUSTRY IN SELECTED OECD COUNTRIES

2016 MINISTERIAL MEETING ON THE DIGITAL ECONOMY

TECHNICAL REPORT 


\section{FOREWORD}

This report was prepared as a contribution to the background report of Panel 4.1 "New markets and New Jobs" of the OECD Ministerial Meeting on the Digital Economy, 21-23 June 2016, Cancún (Mexico). It presents new estimates of the impact of ICT investments on i) total labour demand; ii) labour demand by skill level; and iii) labour demand by industry in selected OECD countries over the period 1990-2012.

The report was prepared by Vincenzo Spiezia, Michael Polder and Giorgio Presidente, OECD, for the Working Party on Measurement and Analysis of the Digital Economy (MADE). A voluntary contribution by Telecom Italia is gratefully acknowledged.

The report was approved and declassified by the Committee on Digital Economy Policies (CDEP) on 13 May 2016 and prepared for publication by the OECD Secretariat.

Note to Delegations:

This document is also available on OLIS under reference code: DSTI/ICCP/IIS(2015)1/FINAL

This document and any map included herein are without prejudice to the status of or sovereignty over any territory, to the delimitation of international frontiers and boundaries and to the name of any territory, city or area.

The statistical data for Israel are supplied by and under the responsibility of the relevant Israeli authorities. The use of such data by the OECD is without prejudice to the status of the Golan Heights, East Jerusalem and Israeli settlements in the West Bank under the terms of international law.

(C) OECD (2016)

You can copy, download or print OECD content for your own use, and you can include excerpts from OECD publications, databases and multimedia products in your own documents, presentations, blogs, websites and teaching materials, provided that suitable acknowledgment of OECD as source and copyright owner is given. All requests for commercial use and translation rights should be submitted to rights@oecd.org. 
TABLE OF CONTENTS

FOREWORD

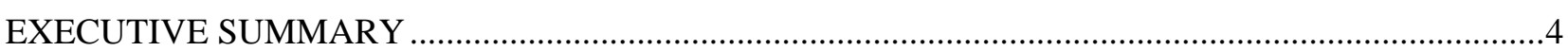

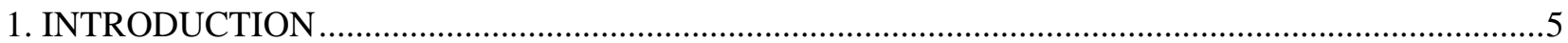

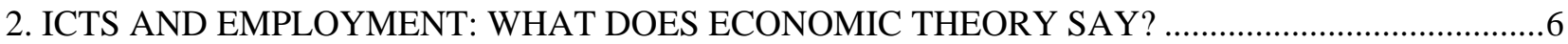

3. INNOVATION AND EMPLOYMENT: FINDINGS FROM RECENT STUDIES................................10

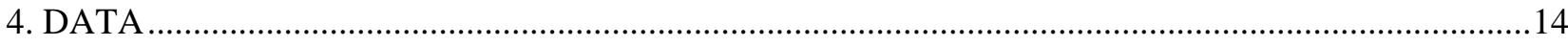

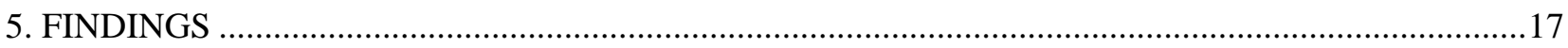

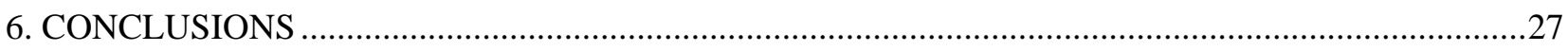

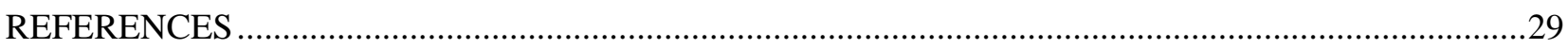

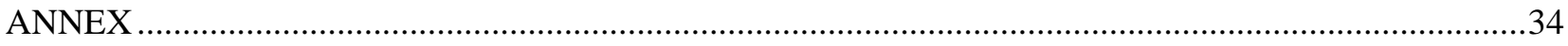

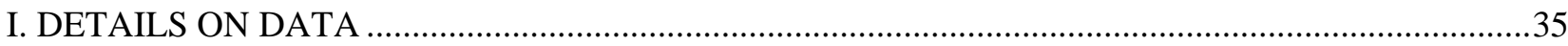

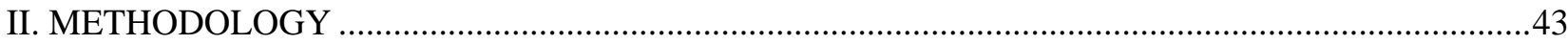




\section{EXECUTIVE SUMMARY}

Information and communication technologies (ICTs) are driving major transformations in the labour market. By increasing labour productivity, ICTs enable the production of more goods and services with less labour, thus leading to the possibility of technological unemployment. At the same time, innovation creates new employment opportunities in different industries and in newly created markets.

This paper examines the effects of ICT investments on i) total labour demand; ii) labour demand by skill level; and iii) labour demand by industry in selected OECD countries over the period 1990-2012. The findings suggest that ICT investments had temporary effects - positive in some periods, negative in others on total labour demand and labour demand by skill but permanent effects on labour demand by industry.

ICT investments are estimated to have raised total labour demand in most countries over the period 1990-2007 but to have reduced it after 2007. In the latter period, the decrease in total labour demand has been accompanied by polarisation in favour of high and low skills and against medium skills. Yet, the effects on both total labour demand and polarisation are estimated to disappear in the long run.

Changes in total labour demand have occurred through a process of reallocation across industries. ICT investments are estimated to have reduced labour demand mostly in manufacturing, but also in information and communication, business services, transport and accommodation, as well as in trade and financial services. Sectors where ICT investments are associated to some increase in labour demand include government and care, culture, recreation and other services, as well as construction.

These findings call for policies to foster growth in industries where ICTs have positive employment effects, e.g. by stimulating ICT adoption by firms in these industries, and to accompany workers along the transition to new jobs, including skills development and temporary income support. 


\section{INTRODUCTION}

There is broad recognition that the digital economy has a great potential to enhance productivity, incomes and well-being. At the same time, there is growing concern that successive waves of investments in digital technologies have contributed to job losses, wage stagnation and rising wage inequality.

Looking back, it is important to note that major technological innovations have always been accompanied by extensive transformations in the labour market. By increasing labour productivity, innovation enables the production of more goods and services with less labour, thus leading to the possibility of technological unemployment. At the same time, innovation creates new employment opportunities in different industries and in newly created markets.

Economic history shows that, after a period of disruption, economies have continued to generate enough jobs for their workforce, although some argue that digital technologies may replace labour more than any other technology before.

Against this background, this paper provides new estimates of the effects of ICT investments on i) total labour demand, ii) labour demand by high, medium and low skill level, and iii) labour demand by industry in selected OECD countries over the period 1990-2012.

Looking at the total economy enables measurement of both the positive and negative employment effects of ICTs, which recent studies at the firm or industry level cannot account for. The findings suggest that ICT investments have no effects on total labour demand and labour demand by skill in the long run. A permanent decrease in the user cost of ICT capital reduces labour demand per unit of output (substitution effect) but it increases output by the same proportion (scale effect).

The long-run neutrality for the total economy is the result of different patterns across sectors. In particular, the findings suggest that ICT tends to decrease employment in the manufacturing sector, but such a decrease is compensated by increases in employment in some services. This finding shows a process of reallocation, where employment shifts from more traditional sectors activities to new economic activities.

The paper is organised as follows. Section 2 presents the main insights of the economic theory on the impact of technological change on the labour market. Section 3 reviews the related literature and discusses findings from recent studies. Section 4 describes the datasets used in the analysis while Section 5 presents the main results. Section 6 concludes. The Annex provides detailed information on the data and the methodology of the analysis. 


\section{ICTS AND EMPLOYMENT: WHAT DOES ECONOMIC THEORY SAY?}

Each major technological wave in modern economic history - the industrial revolution, the development of the assembly line, the mass production of cars or the first generation of personal computers in the early 1980's - has raised strong anxiety about employment. However, after a period of disruption, market economies have typically been able to continue to generate enough jobs for their workforce (Mokyr et al., 2015; Autor, 2015). There are two main reasons for this outcome.

One reason is that, while innovation may reduce labour demand and lead to unemployment, it also triggers a number of automatic market adjustments that tend to compensate for the direct decrease in labour demand (OECD, 1994; Spiezia and Vivarelli, 2002). The analysis of the effects of innovation on employment goes through the history of modern economics, e.g. Say, Ricardo, Marx, Hicks, Marshall and Keynes, among others. The results of this analysis are known in the economic literature as "compensation theory".

Figure 1 provides an illustration of the opposing forces at play. Changes in employment (L) are the results of growth in output $(\mathrm{Y})$ and the changes in the quantity of labour required to produce one unit of output $(\mathrm{L} / \mathrm{Y})$. As shown in the figure, ICTs have an impact both on labour requirements and on output.

Figure 1. Effects of ICTs on employment

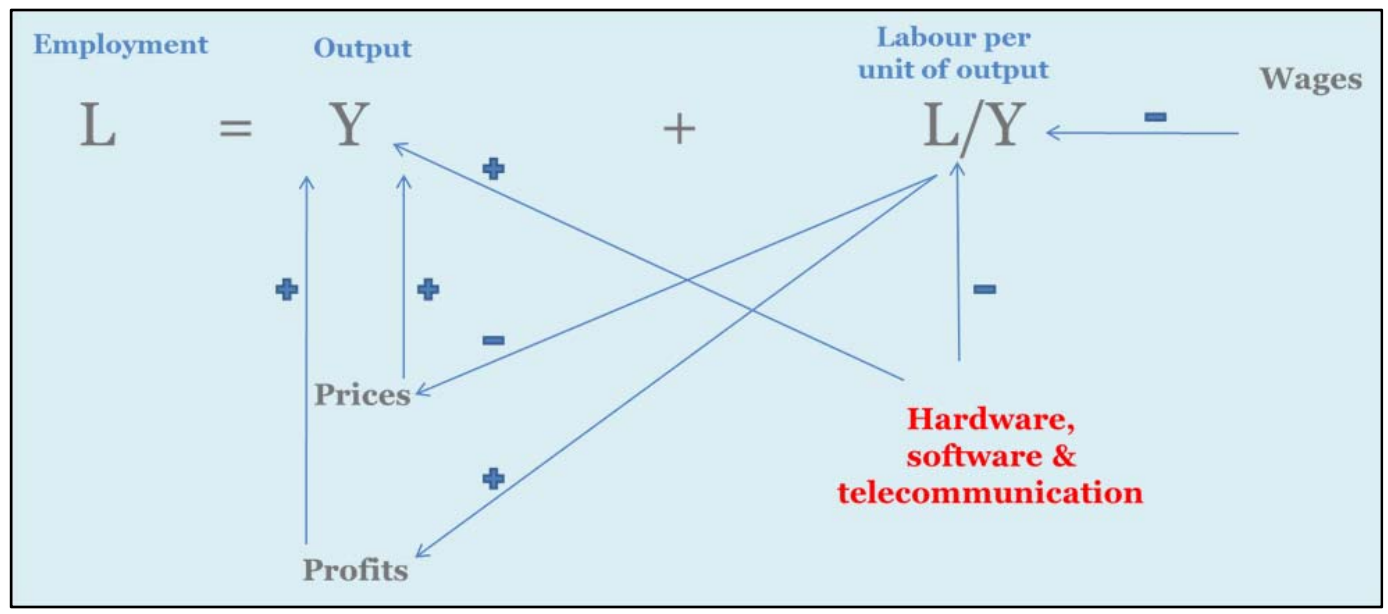

To start with, it is useful to distinguish between process innovations and product innovations. A process innovation increases productivity and reduces unit costs whereas a product innovation results in the commercialisation of new goods and services. Interestingly, ICTs comprise both process innovations, 
e.g. computer-controlled machineries, automated inventory flows, and product innovations, e.g. smartphones, e-books, etc.

By increasing total productivity, ICT process innovations permit to produce a given amount of goods and services with less employment, thus leading to the possibility of technological unemployment. This effect is stronger the larger the labour-saving bias $^{1}$ of the new technology, i.e. the more ICTs reduce the demand of labour relative to that of capital, at constant input prices. The labour-saving bias may be different depending on the type of labour, e.g. ICTs might be biased against low-skill workers and towards high-skill labour.

At the same time, ICT process innovations lead to lower unit costs of production. In a competitive market, this decrease is translated into lower prices, which stimulate higher demand for products. In turn, higher demand generates additional production and employment (compensation "via decrease in prices"). The strength of this effect depends positively on two factors: first, the degree of competition in the product markets; and, second, the price elasticity of final demand.

In less competitive product markets, the decrease in unit costs induced by ICTs is not fully translated into prices and generates extra-profits for the innovative firms. Part of these extra-profits is directly reinvested and increases production and employment in the capital good sector (compensation "via increase in machineries"). The other part provides additional income for share-holders (as dividends) and workers (through wage bargaining), who may spend it on higher consumption or save it. Higher consumption directly increases aggregate demand while savings are lent through the financial system to finance investment by firms and consumption by households. Through these different channels, the increase in income generated by ICTs raises aggregate demand, production and employment (compensation "via increase in income"). The strength of these effects would be larger the higher firms' propensity to invest, the higher households' propensity to consume and the higher the efficiency of the financial system to reallocate savings.

The direct effect of ICT process innovation on employment may be further compensated by a decrease in real wages, which leads to an increase in the labour-intensity of production and/or to a decrease in unit production costs (compensation "via decrease in wages"). The strength of the former effect depends on, first, the degree of substitutability between labour and the other production inputs and, second, the degree of wage flexibility in the labour market. The latter effect is the compensation "via decrease in prices” discussed above.

The commercialisation of new ICT goods and services increases consumption and production and raises the demand for labour (compensation "via new products"). This effect would be larger the lower the substitutability of new products with existing ones and the higher the labour intensity of the production of the new products. In respect to the latter factor, one may expect the labour intensity of ICT products to decrease faster than in other industries, as ICT producing industries are the most intensive users of ICT process innovations.

The other reason for stable employment rates despite fast technological progress is that, while new technologies make some jobs redundant, they also raise the demand for others (Autor, 2015a). Economic history provides plenty of such examples. In the 1920, passenger cars displaced equestrian travel and the related occupations but the roadside motel and fast food industries rose up to serve the "motoring public" (Jackson, 1993). Higher income generated in high-tech industries may also result in higher demand and employment in low-tech services, e.g. restaurants, cleaning and other personal services (Moretti, 2012; Mazzolari and Ragusa, 2013). 
The diffusion of automatic teller machines (ATM), for instance, resulted in raised employment in the banking sector by lowering operating costs in branches and freeing up time for clerks, who could provide a wider range of more complex services to their costumers (Bessen, 2015). Figure 2 shows the evolution of employment for bank tellers, against the number of ATMs installed for several countries over 1994-2004. Although ATMs are a technology with a clear potential for displacing bank tellers, the Figure suggests that in some countries - but not all - both ATM and bank tellers increased.

Figure 2. Employment of bank tellers and ATMs (1994-2004)

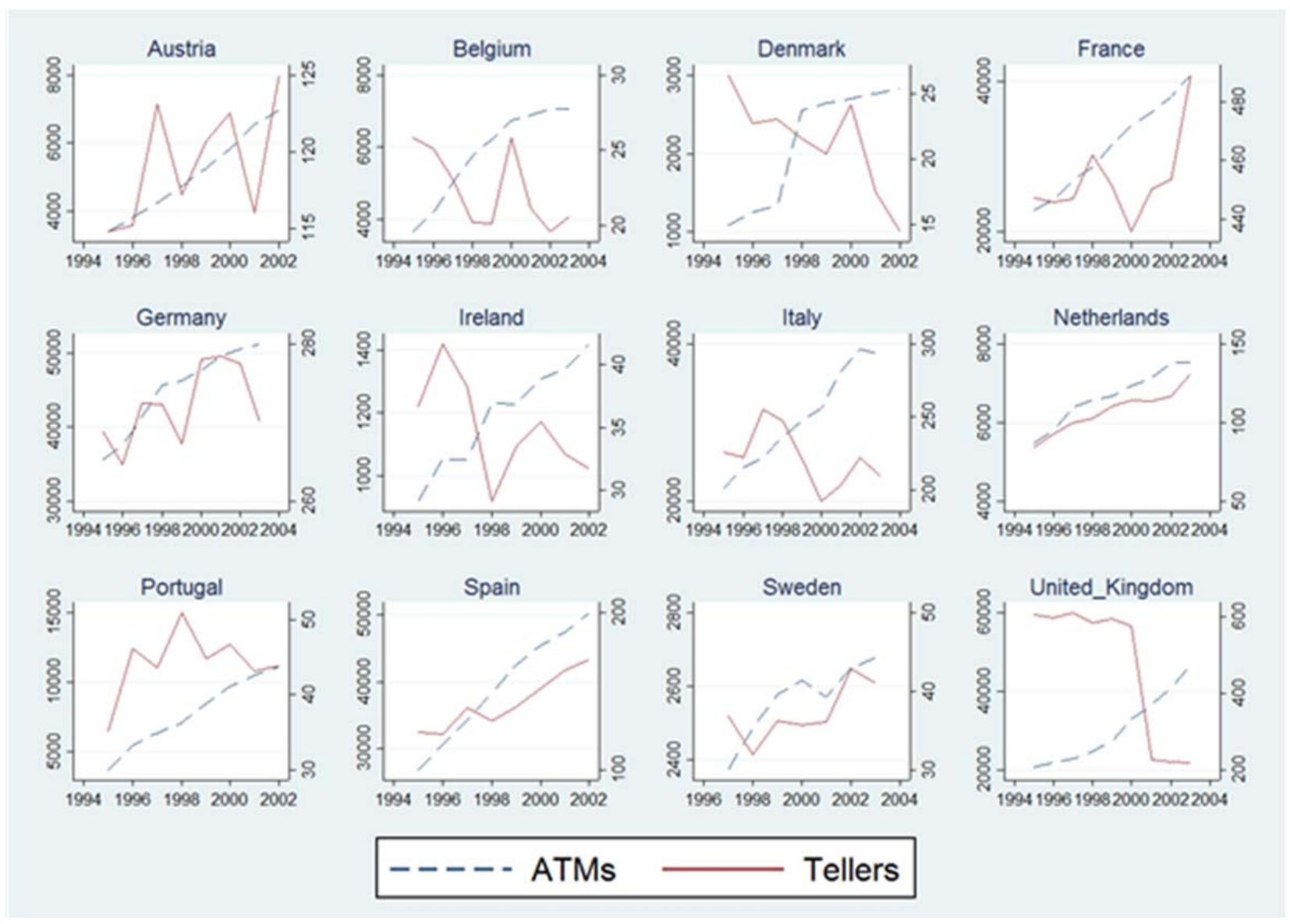

Source: OECD, based on Eurostat and Comin and Hobijn (2009).

The skills required in the digital economy, therefore, are likely to be different. Some skills are sectorspecific and the sectorial re-composition triggered by digital technologies will change the balance among these skills. More fundamentally, skills requirements will change within both sectors and occupations.

Digital technologies tend to substitute for workers in carrying out simple cognitive and manual activities following explicit rules ("routine" tasks), while computers complement workers in carrying out problem-solving and complex communication activities ("non-routine” tasks). Non-routine tasks can either be associated to conceptual jobs at the top end of the wage distribution, e.g. managerial and professional positions, or manual jobs at the bottom end of the distribution, e.g. manual services. Workers that perform manual or cognitive tasks that lend themselves to automation or codification (e.g. book-keeping, monitoring processes, processing information) are, in turn, concentrated in the middle of the wage distribution. Provided that routine and non-routine tasks are imperfect substitutes, the diffusion of digital technologies increases the demand for jobs with non-routine tasks at the expense of jobs with routine tasks (Autor, 2013). 
It is a matter of current debate to what extent the job and wage polarisation observed in some countries in recent years is related to "routinisation". A number of recent studies find evidence that job polarisation in the United States and in Europe is accounted for by declining demand for routine tasks (Autor et al., 2006 and 2008; Goos et al., 2011; Van Reenen, 2011; Autor and Dorn, 2013; Hynninen et al., 2013) but evidence on a direct link between ICT use and demand for skills is rare, with Michaels et al., 2014 being an exception. More analysis is needed to disentangle the effects of digital technologies on job polarisation from the effects of international trade, offshoring and changes in consumer preferences.

Although its effects on polarisation remain unclear, there is broad recognition that the shift from routine to non-routine tasks is likely to remain a long-run feature of labour demand in the digital economy. OECD analysis also shows that, as increasing use of digital technologies is reshaping business models and firms' organization, complementary skills, such as information-processing, self-direction, problem-solving and communication, become more important (OECD, 2016a).

The second major implication of the labour market transformation triggered by digital technologies is that their labour-saving effects hit employment immediately while new job opportunities emerge only slowly. New job opportunities are likely to appear in different industries producing for new markets, in new firms or in established firms adopting new business models, and will require different skills. Therefore, new markets have to be created, assets transferred across sectors, business know-how built up and new skills developed. All of this takes time and involves trial and error.

Furthermore, several studies suggest that the pervasive ongoing developments in artificial intelligence and big data make it possible that, in the near future, a large proportion of jobs currently carried out by workers could be performed by machines (Frey and Osborne, 2013; Elliot, 2014). To what extent these technological possibilities will ultimately result into job displacement depends not only on technology, but also on consumers' preferences and other market factors. For instance, most functions of bank clerks can already be performed by ICTs today but many people still prefer negotiating a loan with a human being than with an algorithm. Yet, a new wave of labour-saving ICT innovations is expected to diffuse across OECD economies and societies in the forthcoming years.

How disruptive these technological developments will be for labour markets is a matter of current debate. Some argue that digital technologies have a stronger labour-saving bias than other major technologies in the past so that "digital labour...is substituting for human labour" on an unprecedented scale (Brynjolfsson and McAfee, 2011). Others (Gordon, 2012; OECD, 2015a) observe that productivity has been growing less rapidly over the last 10-15 years than in the 1960's, which was a boom period for employment, and forecast slow productivity growth in future (Gordon, 2016).

It is way too early to foresee whether in a more or less distant future digital technologies will completely replace human labour and lead to the "end of work" (Rifkin, 1996). The idea has surfaced before in history in the writings of authoritative thinkers (e.g. Russell, 1935; Keynes, 1963) but has not become true so far. However, it is important to note that, if such a prediction was confirmed, economies and policies with them - would have to face a very different set of issues: from "how to make the best use of scarce resources" to "how to redistribute abundance". For instance, if robots did all work instead of humans, where would people get their income from? What incentives would drive economic activities if income produced by robots were fully re-distributed through taxes and subsidies? Who will own the robots? Clearly, these are challenging questions.

While it is worth to monitor technological developments and try to anticipate their implications on jobs and markets in the future, the present paper focuses on the employment effects of ICTs in recent years. 


\section{INNOVATION AND EMPLOYMENT: FINDINGS FROM RECENT STUDIES}

Many empirical studies have analysed the relationship between innovation and employment. While only few of them focus on ICTs, their findings shed light on the effectiveness of the compensation mechanisms discussed in the previous section.

In the 1980s and 1990s, macroeconomic analysis dominated the research on the employment effects of innovation (e.g. Freeman and Soete, 1994; Layard and Nickell, 1994; Machin and Van Reenen, 1998) whereas more recent analyses on this topic have been carried at the sectoral or firm level. Given the scope of this paper, this section reviews the latest studies only (see Sabadash, 2013 for a review of earlier studies).

In general, sectoral studies show that structural change is the driving force behind employment growth, with opportunities for both innovation and for jobs being sector-specific. Industry-level evidence for the 1990's and early 2000's in Europe suggests that the decrease in manufacturing employment was due to a combination of weak final demand, increasing wage, and the prevalence of labour-saving process innovations over product innovations (Bogliacino and Pianta, 2010; Bogliacino and Vivarelli, 2011). Job losses occurred mostly in large firms, among low-skilled workers, in ICT and capital-intensive industries and in the financial sector. Job creation was concentrated in industries with high demand growth and those where product innovation dominated process innovation, as well as in open economies specialised in innovative and fast growing activities.

While the positive employment effects of product innovation are confirmed by firm-level studies, the effects of process innovations range from negative to positive depending on the specification and the dataset. A series of studies on European CIS (Community Innovation Survey) data based on a common micro-funded model (Peters, 2004; Harrison et al., 2008) find out that employment losses are largely concentrated in non-innovating firms while employment growth is mainly driven by the introduction of new products. Process innovation was found to have negative employment effects only in German manufacturing industry.

Hall, Lotti, and Mairesse (2008) run a similar model on a panel of Italian manufacturing firms over the period 1995-2003 and find positive employment effects for product innovation but no significant effect for process innovation. Lachenmaier and Rottmann (2011) estimate a dynamic employment equation on a dataset of German manufacturing firms over the period 1982-2002. They find also positive employment effects for different innovation measures, including process innovation. Coad and Rao (2011) find out a positive correlation between employment and a composite innovativeness index (including both R\&D and patents) in US high-tech manufacturing firms over the period 1963-2002. Bogliacino, Piva, and Vivarelli (2011) analyse a longitudinal database covering 677 European manufacturing and services firms over the period 1990-2008 and find a positive impact of R\&D expenditures on employment in services and hightech manufacturing but not in traditional manufacturing.

Finally, Evangelisti and Vezzani (2011) find out that all types of innovation - including organisational innovation - affect employment indirectly by improving performances, leading to higher sales and more jobs. However, the classical distinction between product and process innovation is not able to capture these 
differentiated effects. Innovation strategies characterized by a combination of product, process and organizational innovations show the strongest positive impact on employment, whereas negative direct effects of process innovations are found only in the manufacturing firms when process innovations are combined with organizational changes.

Different measures of innovation and ICTs are likely to explain to a large extent the different findings of these studies. In a study on Germany, Severgnini (2009) provides an interesting comparison among three different measures of ICTs: 1) a time trend, 2) the ratio of ICT investment to output; and 3) the contribution of ICTs to total factor productivity. These measures give opposite results. When ICTs are measured by a time trend, their employment effects tend to be negative in the short run and positive in the long run. However, long-run effects become statistically not significant when labour and product market regulations are controlled for. The second measure - the ratio of ICT investment to output - has mixed effects on employment while the third measure - the contribution of ICTs to total factor productivity - has negative effects in both the short and the long run.

While firm-level analyses permit a richer characterisation of innovation strategies and avoid the confounding effects from averaging different behaviours at the sectoral or macro level, they miss out the employment effects that ICTs may have in other firms or industries. First, firm-level databases are, in general, not representative of all firms and tend to be biased towards large manufacturing ones. Second, micro-level studies do not distinguish whether employment growth in innovative firms results in net job creation - through "market expansion" - or occurs at the expense of their rivals - through "business stealing”. For example, Greenan and Guellec (2000) find that positive employment effects of process innovation can disappear at industry level due to a business-stealing effect in France.

In addition, even when the business stealing effect is accounted for, firm-level analysis does not measure to what extent the same innovation that destroys jobs in one industry may result in job creation in a different industry via the compensation mechanisms discussed in section 2 . Recent estimates of the ICT employment multiplier based on input-output analysis suggest that these indirect effects are sizable. Such multipliers measure the overall increase in employment generated by 1 additional job in the ICT industry. Katz (2012) reviews the broadband employment multiplier estimated by different studies: their value vary between 1.92 in Germany and 3.6 in the United States. Moretti (2012) argues that the high-tech job multiplier is as high as 5: for each job created in the software, technology and life-sciences industries in the United States, five new jobs are indirectly created in the local economy, 2 in high-skill occupations (e.g. doctors and lawyers) and 3 in low-skill occupations (e.g. waiters, barbers and store clerks).

Moreover, ICTs are generating completely new goods and services, which open up new markets and generate new jobs (compensation "via new products”). Mobile applications (“apps)" are an example in point. The number of apps has been increasing rapidly, as have the associated jobs: not just app developers themselves, but also all those who work upstream and downstream in the apps eco-systems to deal with infrastructure, technical issues related to security, compatibility, interoperability, as well as marketing, sales, and customer services (see for example ICTC, 2012; OECD, 2013a).

The size of the job multipliers associated to the development of "apps" is a subject of debate among researchers. Mandel and Scherer (2012) propose a conservative estimate of 1.5, i.e. each new job in the apps industry generates another 1.5 jobs in the rest of the economy. In their study of the employment impact of Facebook apps development in the US, Hann et al. (2011) assume multipliers of 2.4 for the broadband industry, 2.5 for the communication sector and 3.4 for the whole economy.

Against the estimates of these studies, there is also increasing anecdotal evidence of "scaling without jobs" in ICT services, with such companies as DropBox or WhatsApp, that serve millions of customers with very few employees. Producers of ICT goods and services are the most intensive users of ICT process 
innovations, so that, despite high growth in demand, employment growth in ICT and digital content industries may be fairly limited.

Finally, without taking into account the multiplier effects, statistical evidence suggests it to be unlikely that the employment growth within the ICT and digital content sectors itself will become a main engine of employment growth in the years to come (OECD, 2015b). First, ICT employment (the ICT sector plus ICT specialists elsewhere) is just a small share of total employment. In a few countries (Ireland, Finland and Sweden), the employment share reached 6\% and over at its peak (2000/2001) but it is significantly lower in most countries. Second, from 2001 on, employment in the ICT and digital content sectors has been growing at a slower rate than total employment in a majority of OECD countries, both before and after the crisis, although in recent years growth has been slightly higher in these sectors.

Productivity growth generated by the use of ICTs in non-ICT producing industries provides a further potential channel for employment creation. Higher productivity leads to lower prices, which stimulates higher demand for products and higher production. Based on this channel, one would expect faster growth in productivity, production and, possibly, employment in those industries that use ICTs more intensively. Acemoglu et al. (2014), however, show that this has not been the case in US manufacturing industries (excluding the computer-producing sector) over 1980-2009.

The first attempts of relating technology and skills date back to Nelson and Phelps (1966). In a seminal paper, the authors notice that technology adoption requires workers to adapt to new tools and working methods. To the extent that better educated individuals would cope more easily with adaptation, their argument implies that only skilled workers fully benefit from innovation, while unskilled ones would benefit less, or even lose from it.

A vast literature on skill-biased technical change (e.g. Acemoglu, 1998) tries to explain the contemporaneous increase in the supply of college graduates and their wages during the 1980s. The common theme of these theories is that some technologies such as computers and ICTs in general are complementary to educated workers and possibly substitute for less educated ones. This is because sophisticated machinery can replace workers performing "simple tasks", but at the same time they require engineers in order to be set up and operated.

A closer look at these "simple tasks" is the central contribution of the literature on polarisation (e.g. Autor, Levy, and Murnane, 2003). According to this literature, routine tasks are those which are most readily replaced by machines as they tend to be easily codified and executed by computer programs. However, to perform routine tasks, usually mid-skill workers are required, while the lowest category of skills is usually employed in personal services which are inherently difficult to automate. As a consequence, ICTs would hit harder middle-pay jobs, resulting in labour market polarisation.

The idea that ICTs are biased towards high skill workers seems thus predominant, but purely speculative. At the same time, there are competing views on which workers are the true losers from innovation. Supporters of the market polarisation hypothesis expect workers in the middle of the skill distribution to be hit harder. Advocates of the diffusion/adoption literature would point towards the unskilled ones as the main losers instead.

Economic theory is far from having a canonical model on the impact of ICTs on jobs and skills. Therefore, it is useful to review the main findings of the empirical literature. For the sake of exposition, it can be convenient to classify the widely heterogeneous results into two categories, the "optimistic" and the "pessimistic" views. For example, Moretti (2012) belongs to the former category of scholars and estimates that the high-tech job multiplier is as high as 5: for each job created in the software, technology and lifesciences industries in the United States over 2000-10, five new jobs are indirectly created in the local 
economy, 2 in high-skill occupations (e.g. doctors and lawyers) and 3 in low-skill occupations (e.g. waiters, barbers and store clerks).

Frey and Osborne (2013) can be considered among the technological pessimists. They predict that roughly half of broadly defined occupations are at risk of automation over the next decades, independently on their skill content. According to the authors, the only jobs which will remain in the human domain (but not forever) are those characterised by creativity and other intrinsic attributes of humans that give them a comparative advantage over machines.

Autor and Dorn (2013) look at the change in US employment by skill percentile - as measured by wages - over 1980-2005. They observe an increase of employment not only in high-skill occupations but also in the low-skill ones. As opposite, employment stagnated or even decreased in middle-skill occupations. Autor and Dorn (2013) argue that real wages by skill percentile follow a similar path, suggesting that the increase in employment at the two tails of the skill distribution - high and low skills has been driven by an increase in demand rather than supply.

But evidence on market polarisation is mixed. According to some authors, the pattern is not unique to the United States. These broad findings of the growth of non-routine jobs and the decline of routine work has also been documented for many other OECD countries (e.g. Spitz-Oener, 2006; Dustmann et al., 2009; Firpo, Fortin and Lemieux, 2009; Goos, Manning and Salomons, 2009). While the findings of these papers are consistent with the hypothesis of ICT-based polarisation, only one of them (Michaels et al., 2014) establishes a direct link between ICT use and demand for skills. This paper shows that the most educated people work disproportionately in occupations that require relatively little routine cognitive or manual tasks. Middle educated workers are over-represented in occupations that require routine tasks, especially cognitive ones. The work of the least educated workers involves less non-routine cognitive tasks but more non-routine manual tasks.

At the same time, other studies question the very evidence of job polarisation and changes in tasks. Lefter and Sand (2011) argue that the increase in job polarisation in the United States in the 1990s relative to the 1980s is due to a change in the occupational classification that leads to systematic occupational mismatch. When correcting for this problem, their findings show a long-term upward trend in high-skill jobs and a downward trend in some middle-skill jobs, with no major differences between the 1980s and the 1990s. Handel (2012) argues that there is no strong evidence of a general acceleration in skill upgrading in OECD countries following the diffusion of ICTs. He finds no evidence of within-occupation skill change in either the United States or the European countries in 1997-2009. Furthermore, his findings suggest that, contrary to the "routinisation" hypothesis, craft skills and the frequency of repetitive physical tasks have declined over the same period.

Beaudry et al. (2013) argue that in about the year 2000, the demand for skill - more specifically, for cognitive tasks often associated with high educational skill - underwent a reversal in the United States. In response to this demand reversal, high-skilled workers have moved down the occupational ladder and have begun to perform jobs traditionally performed by lower-skilled workers. This de-skilling process, in turn, results in high-skilled workers pushing low-skilled workers even further down the occupational ladder and, to some degree, out of the labour force all together. 


\section{DATA}

This study is based on two distinct datasets. The first one is used for the analysis of total labour demand and labour demand by skill while the second for the analysis of labour demand by industry. Detailed information on both datasets is provided in the Annex.

The first dataset contains information on prices and quantities of ICT and non-ICT capital, as well as on wages and hours worked by three skill categories, high, medium and low. Data on total hours worked and for the total economy are available for 19 OECD countries from 1990 to 2012. Data on hours worked by skills are only available for 14 countries between 1995 and 2012. The dataset is obtained by harmonising data from four different sources: i) the OECD Productivity Database (PRD, 2014), which provides estimates on non-ICT and ICT stocks and user cost; ii) Labour Force and Current Population Surveys ${ }^{2}$, providing hours worked by occupational category; iii) the World Input Output Database (WIOD, 2012), which contains wages by educational attainments until 2009, and iv) the OECD Education at a Glance (EAG, 2013), which collects recent information on earnings by educational attainments, up to 2012.

Capital inputs are measured as capital services: for any given type of asset, there is a flow of productive services from the cumulative stock of past investments. Estimates of capital services in the OECD Productivity Databases are based on the perpetual inventory method (PIM). The price of ICT capital services is the most important information for the purpose of this paper. Technical progress embodied in new, more efficient ICT capital would be "measured" by a decrease in their user cost. This feature provides the rational for assessing the employment effects of ICTs by looking at the impact of ICT user costs on labour demand.

Figure 3. . Change in the user cost of ICT capital, 1990-2012

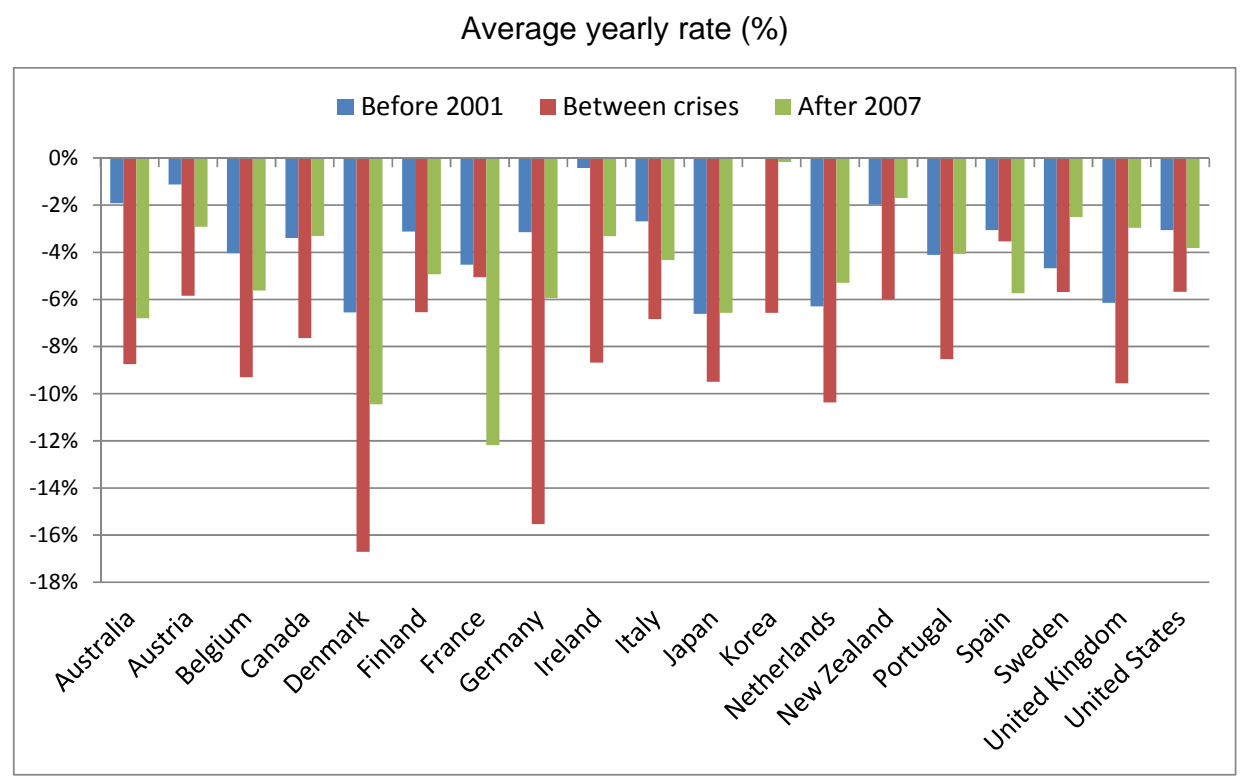

Source: OECD, based on the OECD Productivity Database, 4 September 2014, http://www.oecd.org/std/productivity-stats/.

Figure 3 shows the dynamics of the user cost of ICT capital over 1990-2012 for the three periods early 1990s-2001, 2001-2007 and 2008-2012. These periods correspond to three phases of the business cycle: before the dot.com bubble, after the subprime crisis and between the two crises. ${ }^{3}$ Figure 3 shows two 
main trends. First, in all countries the decrease in ICT user costs has been faster in the second period (2001-2007) than in the first one (before 2001). The 2001-2007 decrease was the largest in Denmark (about $17 \%$ a year) and Germany (just below 16\%). Second, in most countries, the decrease in ICT user costs has continued after the crisis but at a significantly slower rate. This slowdown is likely to reflect lower firms' expectations about future growth due to the crisis. France and Spain are the only exceptions to this trend, as ICT user costs decreased at a faster rate than before.

In studying the impact of technology on employment, it is useful to examine how functional income distribution evolves over time. If technological innovation is biased against a specific particular type of labour, then its share over total labour cost is expected to decrease over time. Figures $4 \mathrm{a}$ and $4 \mathrm{~b}$ show the shares of high, medium and low-skill labour on total wage bill. While the wage shares of high-skill and low-skill labour have been diverging in in all countries, the wage share of medium-skill labour has been declining in some countries and increasing in others. If anything, these trends provide evidence of increasing inequality between high and low-skill labour rather than polarisation against medium-skill labour.

Figure 4. Wage share on total wage bill by skill level
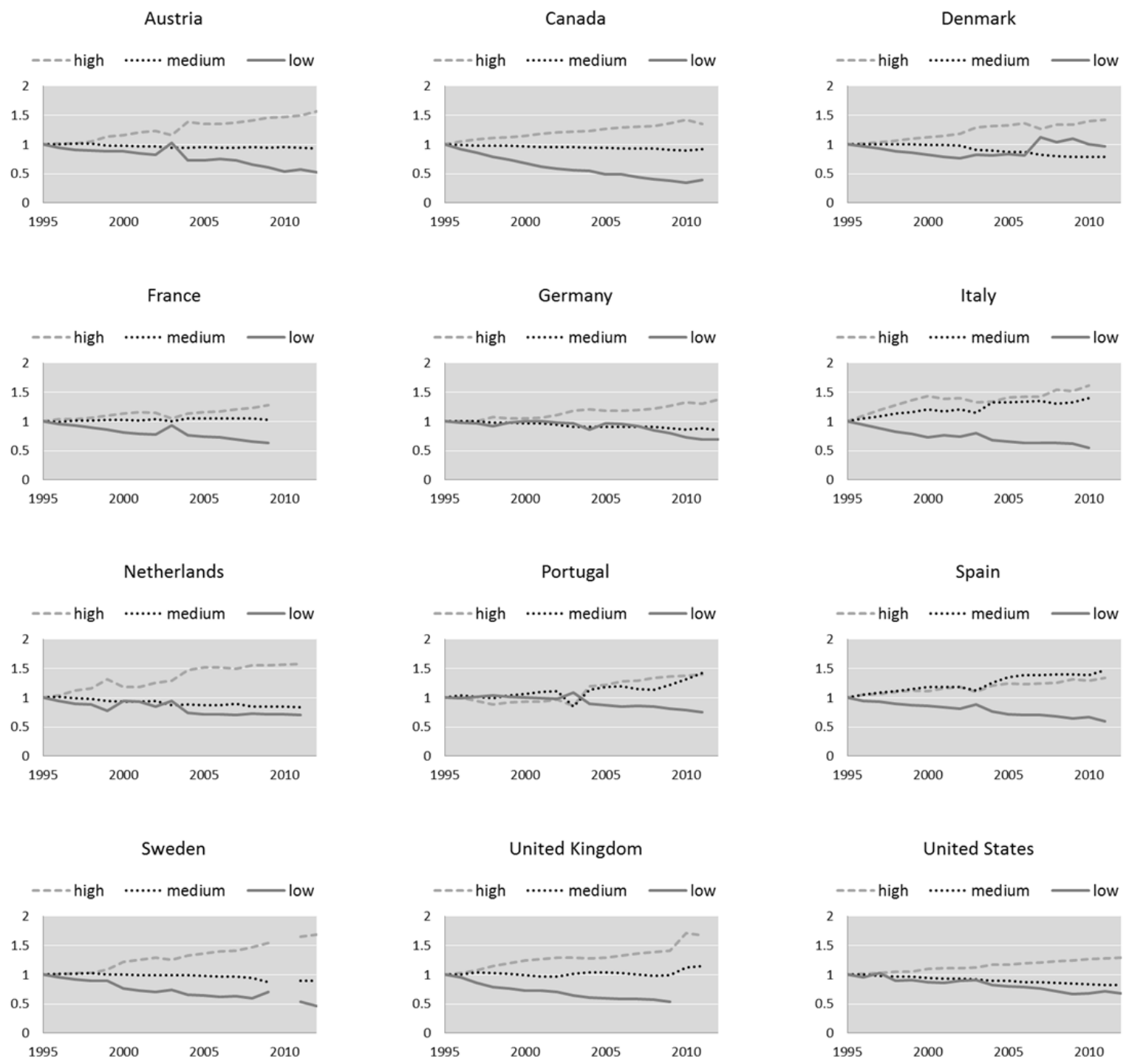

Source: OECD estimates based on World Input Output Database (2012); OECD Education at a Glance (2013b). 
The second dataset is used for the analysis on labour demand by industry. The figures are mainly drawn from OECD's Structural Analysis database (STAN), supplemented by Annual National Accounts figures. Data on value added, labour costs and hours worked are usually readily available for all countries. However, data on capital user costs are not available by industry and have been estimated based on the methodology discussed in the Annex. Due to missing data on self-employment income, labour costs were also estimated based on the common assumption that the cost per hour worked is the same for both employees and self-employed. Finally, incomplete time-series by industries were extrapolated or imputed based on data from other countries, as reported in the Annex.

Figure 5 shows changes in the industry shares of hours worked in the total economy and across countries over the period of the analysis. The most striking changes have been the decrease in Manufacturing to the benefit of Business services. The share of Agriculture has also declined significantly, whereas the share of Government and care has increased by about the same magnitude. Changes in the shares of other sectors are close to zero. In Trade, transport and accommodation, the figures show a shift from self-employment to employees. The opposite seems to have occurred in Construction, where a small decrease in the number of employees is compensated by an increase in self-employment. These changes have been driven by a variety of factors, including changes in consumers' preferences, international trade, outsourcing and technological change. Indeed, the introduction of new technologies drive structural transformations by creating new jobs in certain sectors of the economy, while making other jobs obsolete. The analysis presented in next section tries to disentangle the employment effects of ICTs from those of the other factors mentioned above.

Figure 5. Changes in industry shares of hours worked (all countries, 1996 to 2011)

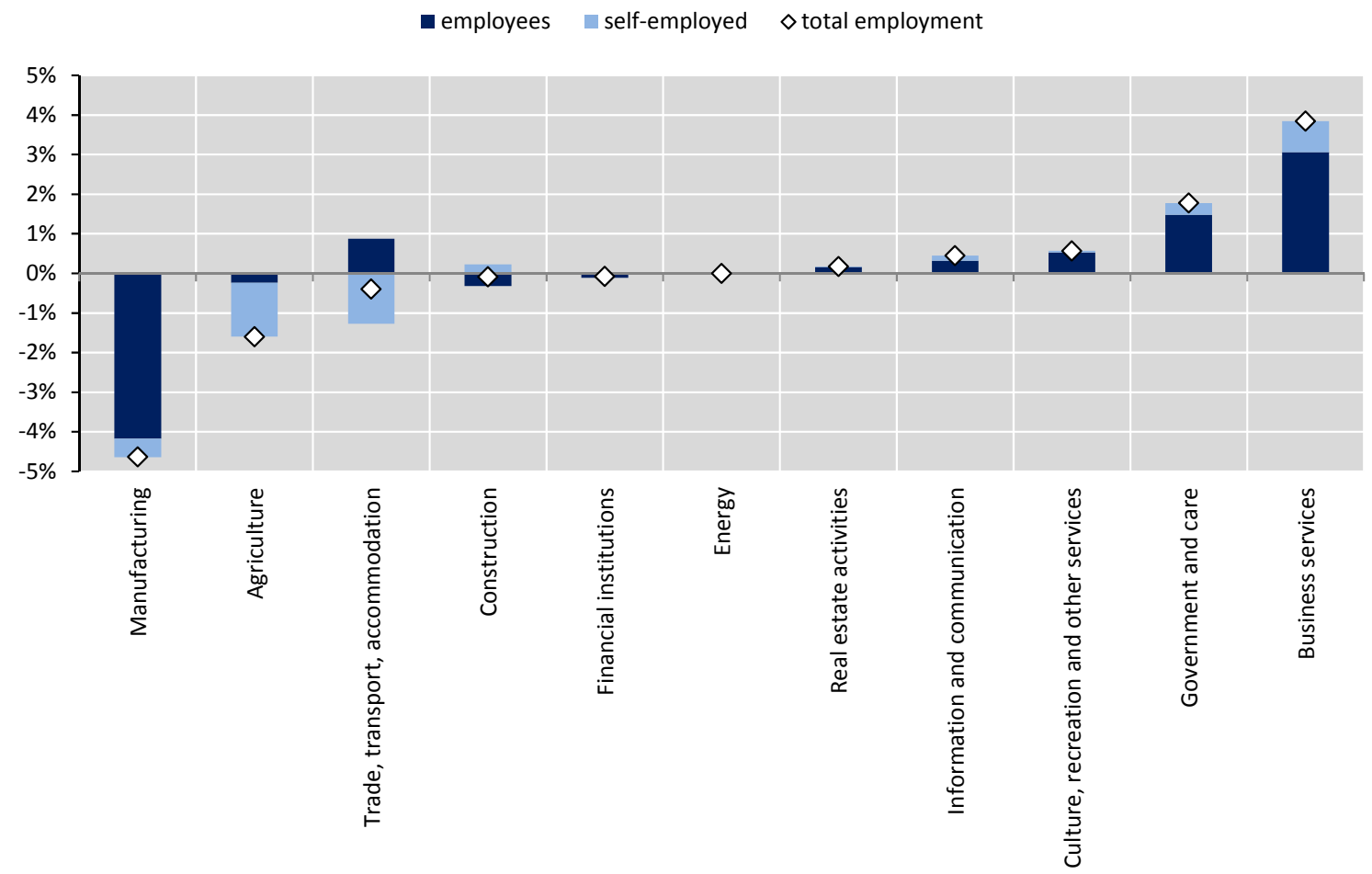

Source: OECD, based on OECD Structural Analysis Database (February 2016).

Based on Australia, Austria, Germany, Denmark, Finland, France, Italy, Netherlands, Portugal, Sweden and the United Kingdom. The first year is 1997 for Denmark and 1998 for the United Kingdom; the last year for Australia is 2010. 


\section{FINDINGS}

This paper analyses the effects of ICTs on employment within the standard labour demand theory. This framework has the advantage to model the employment effects of ICTs as a result of firms' decisions and market mechanisms rather than as a technology-driven outcome.

Fast technological progress in ICTs has led to a rapid decrease in the user costs of ICT equipment and software and to large investments in ICTs. Such investment have resulted into changes in the production mix of labour, ICT capital and other types of capital, on the one hand, and into a decrease in production costs and an increase in final demand, via lower prices and/or higher income, on the other.

The net impact of technological progress embodied in ICT capital on labour demand depends, therefore, on: $i$ ) the extent to which ICT capital substitutes for labour (partial elasticity of substitution); and ii) the extent to which lower unit costs generate higher demand and production via a decrease in prices (price elasticity) and/or an increase in income (income elasticity).

For the total economy, the economic theory predicts that a decrease in price or an increase in income results in a proportional increase in final demand. Therefore, ICT investments increase or reduce labour demand depending on whether the partial elasticity of substitution between labour and ICT capital is smaller or bigger than 1. This condition applies to total labour as well as to each skill level, i.e. high, medium and low-skill labour.

The same is not true at the industry level, where a decrease in price or an increase in income may result in a less-than-proportional increase or even a decrease in the industry's demand and output. As a result, ICT investments may lead to a reallocation of labour across industries even when the degree of substitution between ICT capital and labour is low.

\subsection{Total economy and breakdown by skill}

The main findings on total labour demand and labour demand by skills can be summarised as follows (detailed regression outputs are reported in the Annex).

In the long run, the partial elasticity of substitution between labour and ICT capital is equal to one in all countries. Therefore, a permanent decrease in the user cost of ICT capital reduces labour demand per unit of output but it increases output by the same proportion. In other words, the substitution effect and the demand effect compensate each other completely. As a result, based on these estimates, investments in ICTs do not have any effect on labour demand in the long-run. ${ }^{4}$

In the short run, however, firms cannot change production inputs immediately because of staggered contracts, regulations and other adjustment costs. In addition, ICT investments are likely to trigger a process of reallocation of production inputs across industries and this process takes time. As a consequence, a permanent decrease in the user cost of ICT capital does have an impact on labour demand in the short run. The adjustment path of employment can be described as follows. 
Figure 6. Simulated changes in labour demand following a permanent 5\%-decrease in the ICT user cost

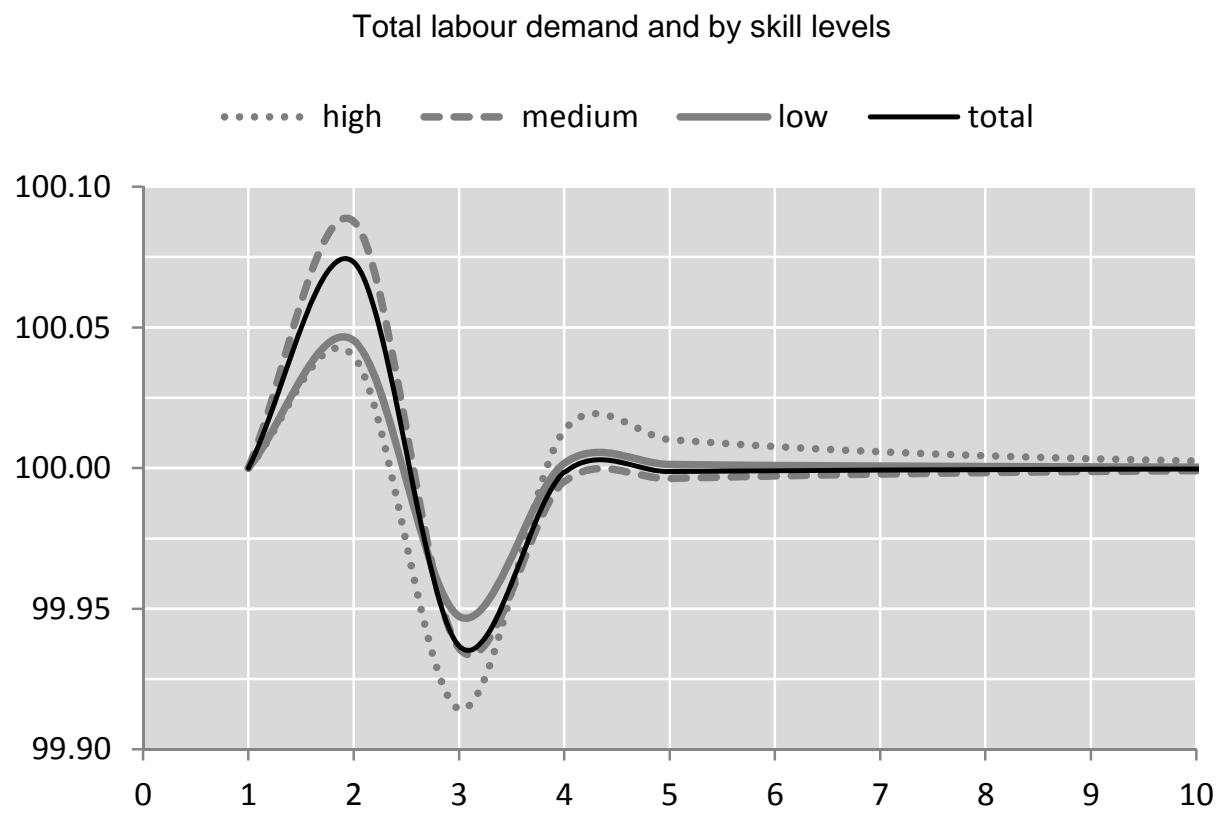

Source: OECD estimates based on the OECD Productivity Database, 4 September 2014, http://www.oecd.org/std/productivitystats/; World Input Output Database (2012); OECD Education at a Glance (2013b).

In the first period, production techniques are not fully flexible because it takes time for firms to change inputs. A decrease in the user costs of ICT capital leads to lower costs and prices and higher demand. As a result, firms hire more and employment increases. In the next period, firms can change their production technique. At a lower user of cost of ICT capital, they invest more in ICTs and reduce labour. As the hiring started in the first period is still producing its effects due to staggered contracts and adjustment costs, firms reduce employment below its long run level. In the following periods, therefore, firms progressively increase employment as to bring it back to equilibrium.

The effect of ICT investment on labour demand is qualitatively the same for all skill levels, although changes are found to be proportionally larger for medium-skill than high and low-skill workers. Furthermore, in the long run, the shares of high, medium and low skilled labour are determined exclusively by their relative prices and not by the user costs of ICT, as well as non-ICT capital. ${ }^{5}$

One important implication of this dynamics is that, in periods where labour demand decreases due to ICTs, the decrease is stronger for medium-skill workers than for high and low-skill ones. This finding is consistent with the job polarisation argument - ICTs reduce the demand for medium skills relative to high and low skills - but also implies that this polarisation is only temporary.

The adjustment path following a permanent decrease in ICT user costs is illustrated in Figure 6. The changes in labour demand are larger the larger the decrease in ICT user costs and the smaller the labour share in total costs. The return of labour demand to its long run level is also slower the smaller the labour share. For the values of the labour share in OECD countries - between 0.65 and 0.88 - the negative employment effects disappear after about 5 years.

This dynamics is compounded by the fact that the permanent decrease in the user cost of ICT capital is not a "one-off" but it has been a continuous trend over more than two decades. Therefore, its employment effects have accumulated over time and become more persistent. In general, the employment 
effect of ICT remains positive for as long as the decrease in ICT user cost occurs at an increasing rate. When the decrease in ICT user cost slows down, the negative short-run effects of past capital accumulation prevail and result in a decrease in labour demand.

Figure 7 shows the change in aggregate employment driven by the accumulation of ICT capital over 1990-2012 for the three periods 1990-2000, 2001-2007 and 2008-2012, as discussed in Section 4.

Figure 7. Estimated changes in labour demand due to ICT investments

Average yearly rates

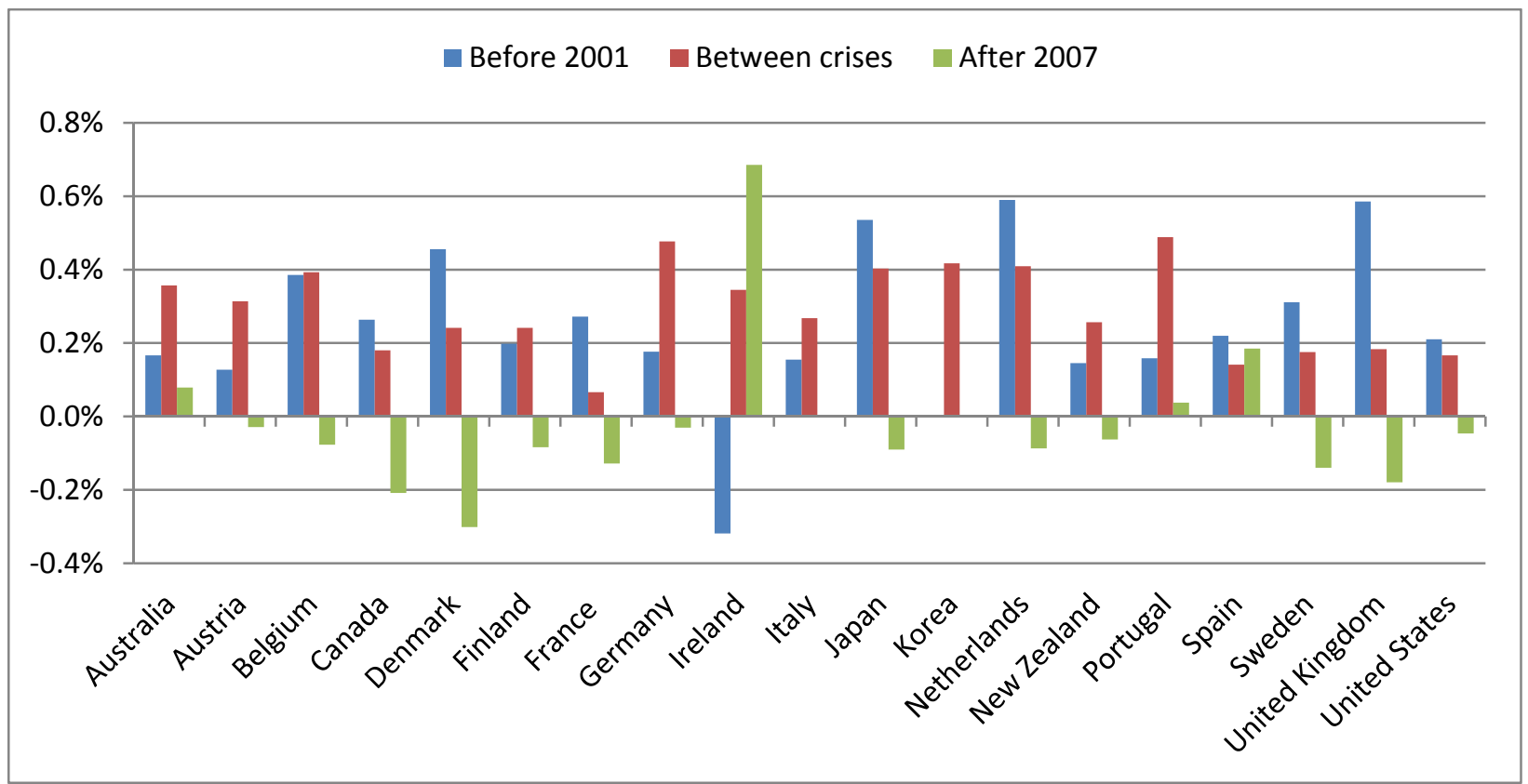

Source: OECD estimates based on the OECD Productivity Database, 4 September 2014, http://www.oecd.org/std/productivitystats/; World Input Output Database (2012); OECD Education at a Glance (2013b).

The estimates suggest that ICT investments have raised employment in both the period before 2001 and the subsequent period 2001-2007 in all countries, with the exception of Ireland in the first period. After 2007, ICT investments have resulted in a small decrease in labour demand in 13 out of 20 countries, ranging from $-0.3 \%$ a year in Denmark to $-0.03 \%$ in Germany. The adjustment pattern shown in Figure 6 suggests that the decrease in the latter period is due to a slowdown in ICT investment (Figure 3) coupled with the negative effects of sustained ICT investments over the previous periods.

The above findings suggest that policies to foster ICT investments would be beneficial to employment. In addition, the cost of temporary job losses due to the accumulation of past ICT investments could be relieved through labour market activation policies and temporary income support.

Figure 8 shows the proportional change in labour demand by country and skill group over the three periods considered. The estimated changes tend to be small in most countries and periods with the exception of medium and low skills in Italy (-1.6\% and $-2.1 \%$ per year, respectively) and Denmark (-1.5\% and $-1.0 \%$ per year) after 2007.

Overall, the estimates do not support neither the hypothesis that ICTs are biased in favour of highskill labour nor the hypothesis of polarisation against medium slills. The demand for high-skill labour often decreased, even in countries characterised by high shares of skilled workers, such as the United States, the 
United Kingdom and Denmark. Labour demand for medium-skill fell more than for high and low skills only in five countries (Austria, Denmark, Italy, Sweden and the United States) and only in the period after 2007.

Figure 8. Estimated changes in labour demand by skills due to ICT investments

Average yearly rates

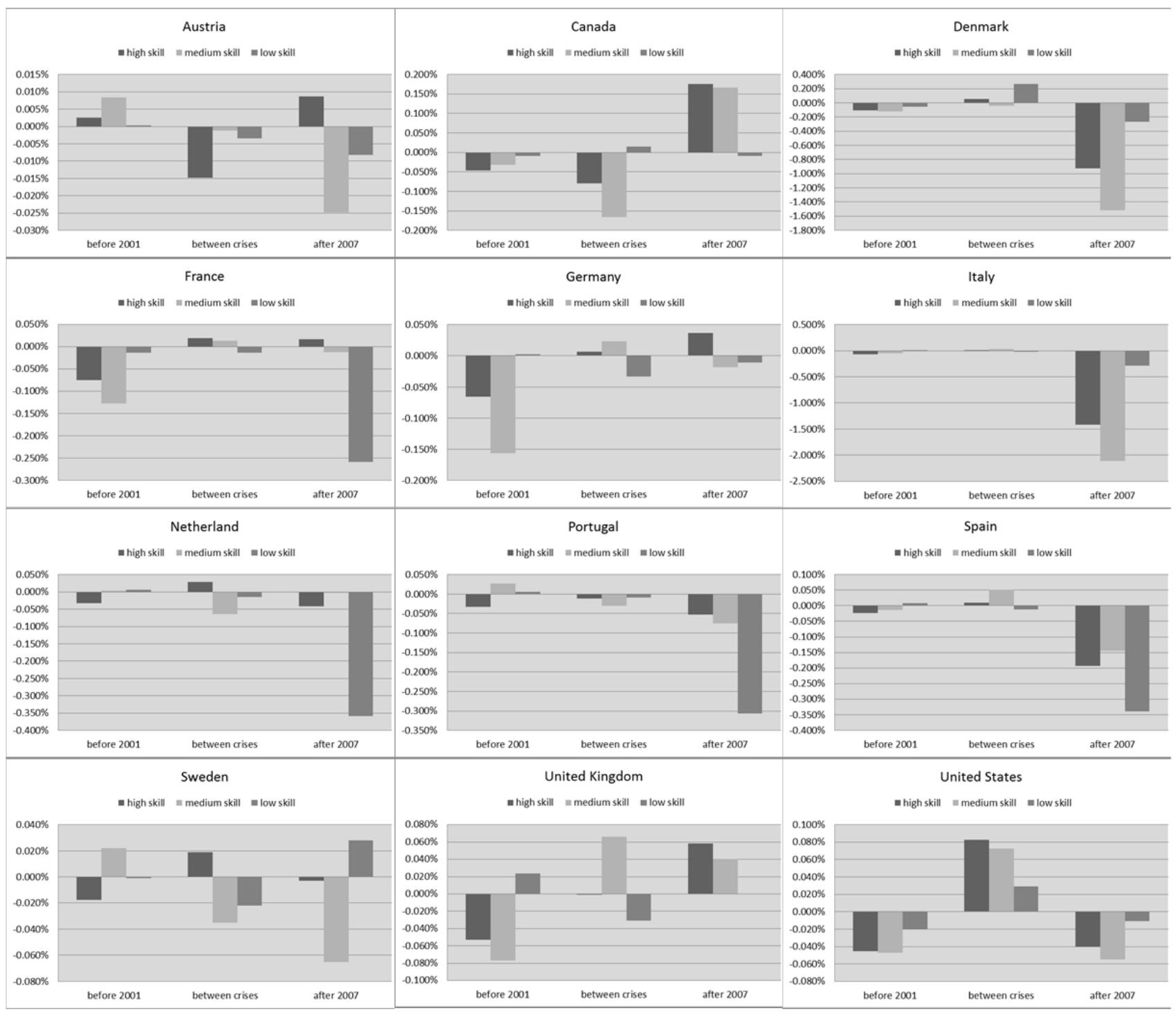

Source: OECD estimates based on the OECD Productivity Database, 4 September 2014, http://www.oecd.org/std/productivitystats/; World Input Output Database (2012); OECD Education at a Glance (2013b).

The classification of high, medium and low skills, therefore, appears a too-simple framework for the analysis of the effects of ICTs on skills demand. This finding has two main implications.

First, the effects of ICTs on skills demand should be examined within skill groups and, more precisely, at the level of occupation. For instance, OECD (2016a) shows that the use of ICT is associated to a different set of tasks performed in each occupation. Some of these tasks require high skills, e.g. problem solving, but other need "softer" skills, e.g. capability to interact with co-workers and clients, which cannot be easily associated to formal education. 
The second implication is related to the capability of workers to perform the set of tasks associated to the use of ICTs. OECD (2016a) shows that a significant proportion of individuals using ICTs at work every day do not have sufficient skills to use these tools effectively. This finding suggests that ICTs may not result in a decrease in labour demand but in slower growth in labour productivity, a hypothesis consistent to the literature on ICTs and human capital (Bresnahan et al., 2002; Oliner et al., 2007). Statistically, this effect implies that the wage growth for individuals with low ICT skills should be lower when they are employed in occupations that use ICTs more intensively. This hypothesis cannot be explored within the labour demand framework developed in this paper but requires an analysis at the level of individuals. Although data availability remains a strong constraint, this is a direction that further work will have to explore.

\subsection{Breakdown by sector}

The findings of this section show that the employment effects of ICTs tend to differ across sectors. The fast decline in ICT user costs over the 1995-2012 is estimated to have resulted in a permanent decrease labour demand in manufacturing and, to a lesser extent, in business services, trade, transport and accommodation. At the same time, lower ICT user costs are associated with a permanent increase in labour demand in culture and recreation as well as in construction.

Figure 9. Substitution effect between ICT capital and labour (by industry, 1995-2012)

$\%$ change in labour demand associated with a $1 \%$ decrease in ICT user costs

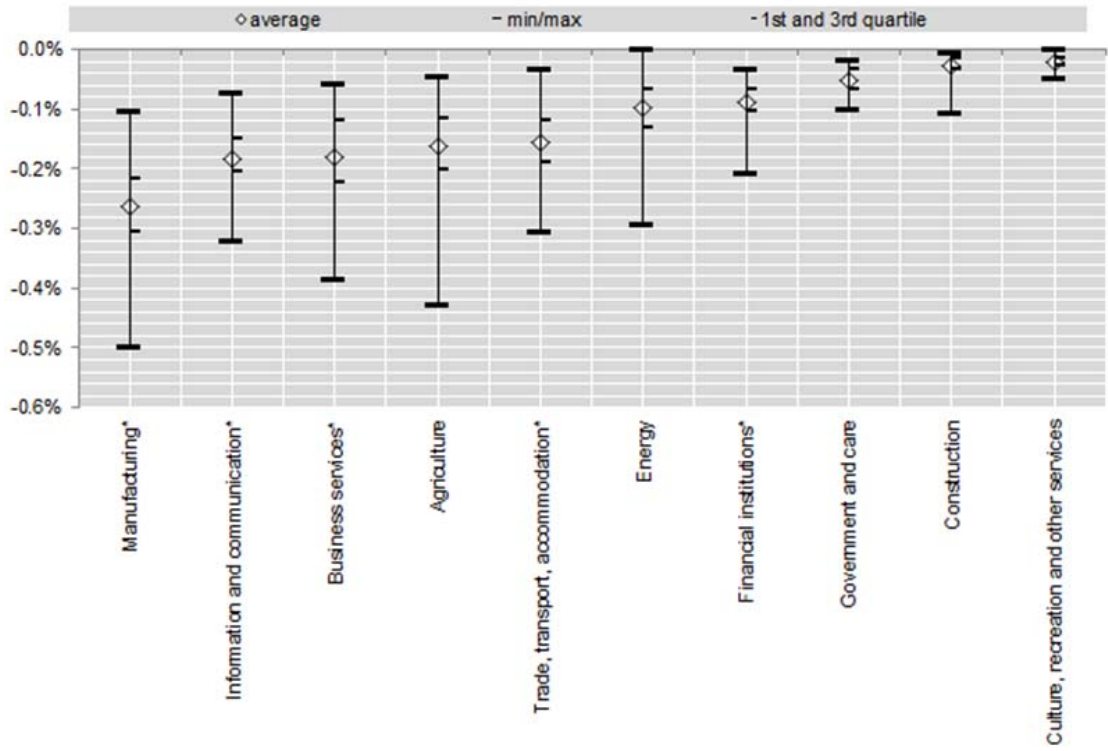

* indicates sectors where the substitution effect is significantly different from zero in a statistical sense.

Source: OECD estimates based on the OECD Productivity Database, 4 September 2014, http://www.oecd.org/std/productivitystats/; World Input Output Database (2012); OECD Education at a Glance (2013b).

While for the total economy the substitution and scale effects are estimated to offset each other (see Section 5.1 above) this does not hold in each sector because the technologies of production and the consumer's preferences are different across sectors. Therefore, the same change in ICT user costs may have different effects on the labour demand in different sectors.

Figure 9 shows the estimated elasticity of substitution between labour and ICT capital, i.e. the proportional change in labour demand following a 1\%-decrease in ICT user costs, at a constant level of 
output. ICT capital and labour are found to be substitutes in all sectors, as shown by the negative values of the elasticity. The largest effect is in manufacturing, where, on average, a 1\%-decrease in ICT user cost reduces labour demand by $0.26 \%$. Other sectors with a sizeable effect are information and communication $(0.18 \%)$, business services $(0.18 \%)$, agriculture $(0.16 \%)$ as well as trade, transport and accommodation $(0.16 \%)$.

The decrease in ICT user costs lead to a decrease in output prices and/or profits, thus to an increase in final demand and in the demand for labour. Figure 11 shows the estimated elasticity of final demand to income (panel a) and prices. The price elasticity is estimated separately for domestic demand (panel b) and exports (panel c).

Agriculture, construction and manufacturing are the only three sectors where income elasticity is below 1, i.e. when income increases, consumers decrease the share of their income spent on the products of these industries. On the contrary, the share of income spent in financial services, business services as well as culture and recreation increases with income.

As for price elasticity, a decrease in price is associate to a more than proportional increase in both domestic demand and exports of financial services and construction. In all other sectors, the price elasticity of exports is below unity. This holds also for domestic demand in manufacturing, culture, recreation and other services, government and care, trade, transport and accommodation, as well as Energy.

Figure 10. Elasticity of final demand to income and price (by industry, 1995-2012)

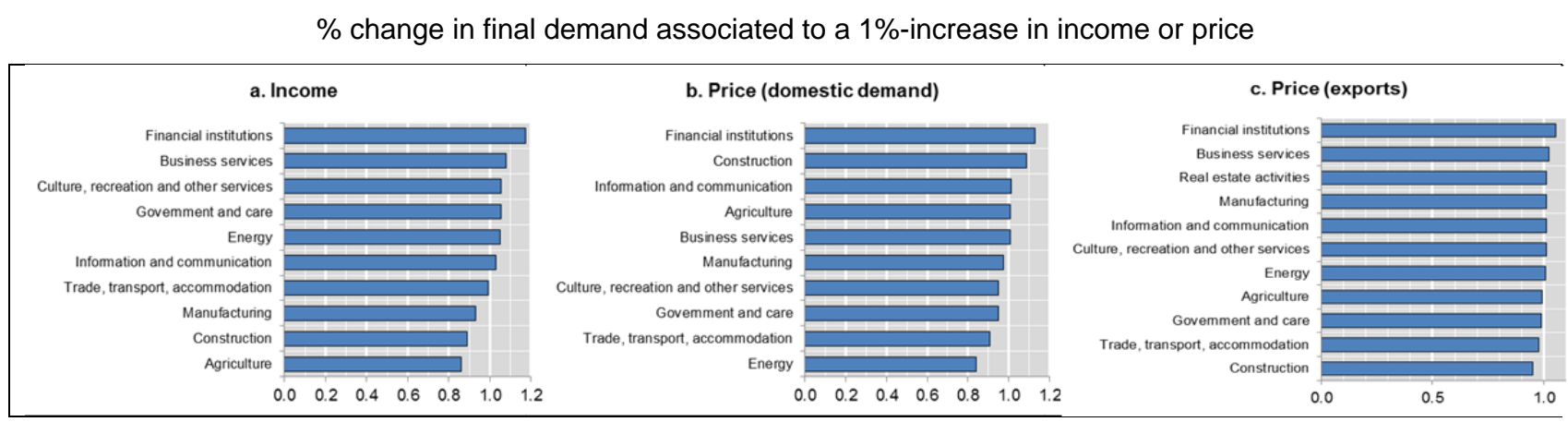

Source: OECD estimates based on the OECD Productivity Database, 4 September 2014, http://www.oecd.org/std/productivitystats/; World Input Output Database (2012); OECD Education at a Glance (2013b).

The overall changes in labour demand results from the balance between (negative) substitution effects (negative) and (positive) demand effects. Figure 11 shows that, in most countries, demand effects outweigh substitution effects in culture, recreation and other services, construction and, to a lesser extent, government and care, energy and agriculture, thus leading to an increase in labour demand in these sectors. In all other sectors, substitution effects prevail and lead to a decrease in labour demand, particularly in manufacturing, business services and trade, transports and accommodation. 
Figure 11. Estimated changes in labour demand due to ICT investment (1995-2012)

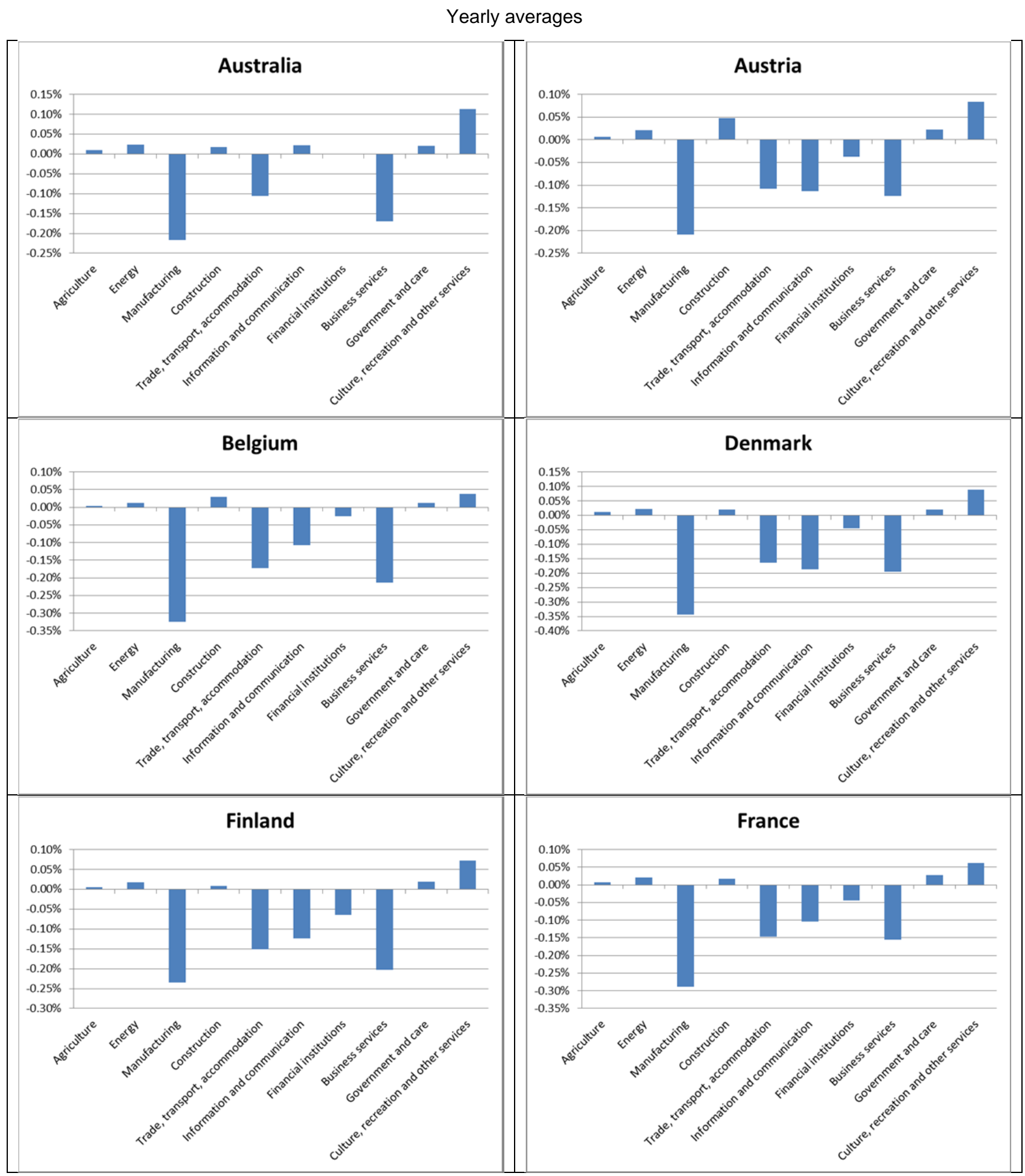




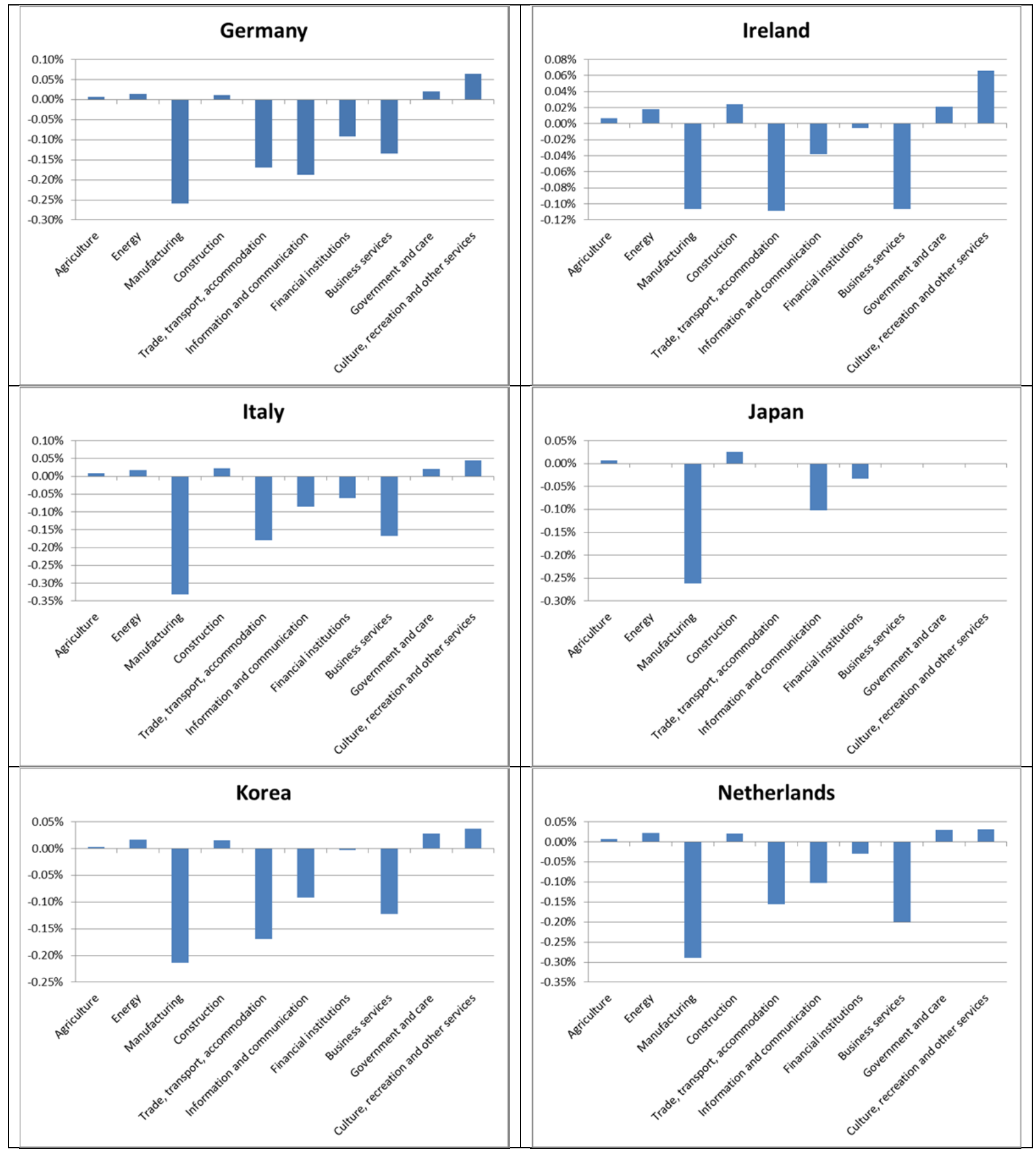




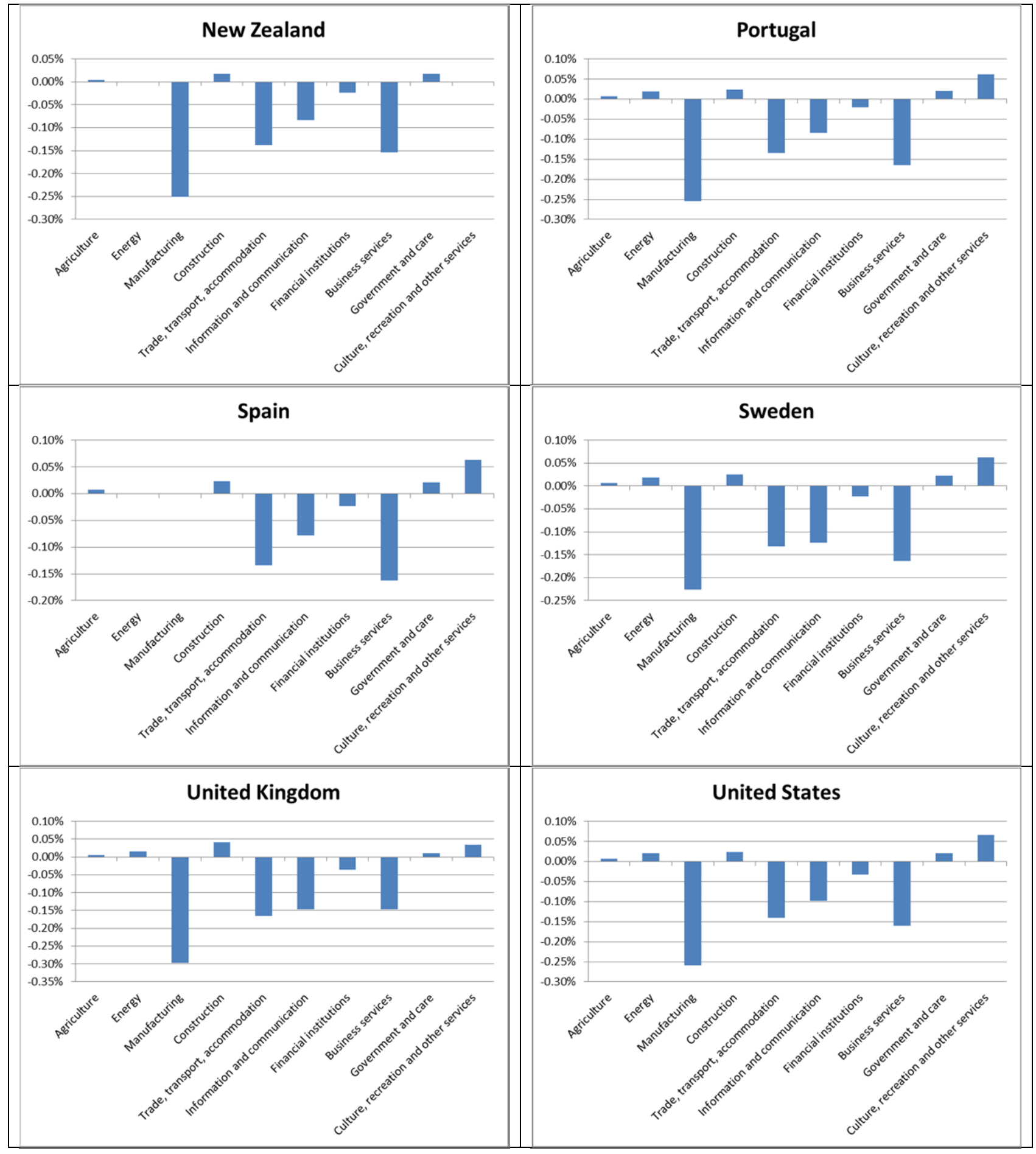

Source: OECD estimates based on the OECD Productivity Database, 4 September 2014, http://www.oecd.org/std/productivitystats/; World Input Output Database (2012); OECD Education at a Glance (2013b).

Note: The following data are not available. Spain: Manufacturing and Energy; New Zealand: Energy and Culture, Recreation and other services; Japan: Energy, Trade, transportation and accommodation, Business Services, Government and care, Culture, Recreation and other services. 
The above patterns are consistent with the finding for the total economy that ICTs have not effect on labour demand in the long run. However, they show that this finding is the result of a process of structural reallocation, for which labour moves from sectors that are negatively impacted to others where ICTs raises demand and output. Although the positive and negative effects by sector tend to cancel out in the long-run, the findings suggest that this process is still ongoing.

These findings call for policies to foster growth in industries where ICTs have positive employment effects, e.g. by stimulating ICT adoption by firms in these industries, and to accompany workers along the transition to new jobs, including skills development and temporary income support. 


\section{CONCLUSIONS}

This study has presented new estimates of the impact of ICT investments on $i$ ) total labour demand; ii) labour demand by skill level; and iii) labour demand by industry in selected OECD countries over the period 1990-2012. Its approach has been to measure ICT technical progress as the decline in the user cost of ICT capital and to estimate the effects of such decline on the demand for labour.

The findings suggest that ICT investments had temporary effects - positive in some periods, negative in others - on total labour demand and labour demand by skill but permanent effects on labour demand by industry.

ICT investments are estimated to have raised total labour demand in most countries over the period 1990-2007 but to have reduced it after 2007. In the latter period, the decrease in total labour demand has been accompanied by polarisation in favour of high and low skills and against medium skills. Yet, the effects on both total labour demand and polarisation are estimated to disappear in the long run.

Changes in total labour demand have occurred through a process of reallocation across industries. ICT investments are estimated to have reduced labour demand mostly in manufacturing, but also in business services, trade, transport and accommodation, as well as in information and communication and financial services. Sectors where ICT investments are associated to some increase in labour demand include culture, recreation and other services, as well as construction and government and care.

These findings call for policies to foster growth in industries where ICTs have positive employment effects, e.g. by stimulating ICT adoption by firms in these industries, and to accompany workers along the transition to new jobs, including skills development and temporary income support. 


\section{NOTES}

According to Hick’s classification of technological progress.

The European data is based on the European Labour Force Survey (extraction from Eurostat). The Canadian data is based on the Canadian Labour Force Survey (extraction from StatCan). The US data is based on the Current Population Survey (extraction from DataFerrett).

As the business cycle was not fully synchronised among countries, these periods are specific to each country, as indicated in Table A1 in the Annex.

Unitary elasticity of substitutions means that, in the long run, production function is equivalent to a CobbDouglas and labour shares are constant.

Economic theory refers to this property as separability, which implies that different types of labour - high, medium and low skills - can be treated as one homogenous input relative the other production inputs, capital, energy, etc. 


\section{REFERENCES}

Acemoglu, D. (1998), "Why do new technologies complement skills? Directed technical change and wage inequality." Quarterly Journal of Economics: 1055-1089.

Acemoglu, D. et al. (2014), "Return of the Solow Paradox? IT, Productivity, and Employment in US Manufacturing”, American Economic Review: Papers \& Proceedings, 104(5): 394-399.

Autor, D. (2015), "Why Are There Still So Many Jobs? The History and Future of Workplace Automation”, Journal of Economic Perspectives, Volume 29, Number 3, Summer 2015, Pages 3-30.

Autor, D. (2013), “The ‘Task Approach’ to Labor Markets: An Overview.” Journal for Labour Market Research 46(3): 185-99.

Autor, D. and D. Dorn (2013) "The Growth of Low-Skill Service Jobs and the Polarization of the U.S. Labor Market”, American Economic Review, 103(5), 1553-1597.

Autor, D., L. F. Katz, and M. S. Kearney (2006), “The Polarization of the U.S. Labor Market.” American Economic Review 96(2):189-94.

Autor, D., F. Levy, and R. J. Murnane (2003). "The Skill Content of Recent Technological Change: An Empirical Exploration”, Quarterly Journal of Economics 118(4): 1279-1333.

Beaudry, P., D. A. Green and B. M. Sand (2013), The Great Reversal in the Demand for Skill and Cognitive Tasks, NBER Working Paper No. 18901.

Bessen, J., 2015. “Toil and Technology”, Finance and Development,52(1).

Bogliacino, F., and M. Vivarelli (2011), “The Job Creation Effect of R\&D Expenditures” IZA Discussion Papers, 4728. Bonn, Germany: IZA.

Bogliacino, F., M. Piva, and M. Vivarelli. 2011. "R\&D and Employment: Some Evidence from European Microdata.” IZA Discussion Papers, 5908. Bonn, Germany: IZA.

Bogliacino, M. and M. Pianta (2010), "Innovation and employment: a reinvestigation using revised Pavitt classes”, Research Policy 39 (6).

Blundell, R. and S. Bond (1998), "Initial conditions and moment restrictions in dynamic panel data models”, Journal of Econometrics, 87, pp. 115-143.

Blundell, R. and S. Bond (1999), “GMM estimation with persistent panel data: An application to production functions”, IFS working paper.

Brynjolfsson, E. and A. McAfee (2011), "Race Against The Machine: How the Digital Revolution is Accelerating Innovation”, Driving Productivity, and Irreversibly Transforming Employment and the Economy, Digital Frontier Press. 
Bresnahan, T.F., E. Brynjolfsson, and L.M. Hitt (2002), "Information Technology, Workplace Organization, and the Demand for Skilled Labor: Firm-Level Evidence”, Quarterly Journal of Economics, Vol. 117, No. 1, pp. 339-376.

Christensen, L., D. Jorgenson and L. Lau (1973), "Transcendental logarithmic production frontiers", Review of Economics and Statistics, 55:28-45.

Coad, A., and R. Rao. 2011. "The Firm-level Employment Effects of Innovations in High-Tech U.S. Manufacturing Industries.” Journal of Evolutionary Economics, 21: 255-83.

Corrado, Carol, J. Haskel and C. Jona-Lasinio (2014), “ICT, R\&D and Non-R\&D Intangible Capital: Complementary Relations and Industry Productivity Growth", $3^{\text {rd }}$ World KLEMS Conference, 19-20 May 2014, Tokyo http://www.researchgate.net/publication/266209151.

Dustmann, C., J. Ludsteck, and U. Schönberg (2009) “Revisiting the German Wage Structure”, Quarterly Journal of Economics, 124(2).

Elliot, Stuart W, (2014), “Anticipating a Luddite Revival”, Issues in Science and Technology, Issue 3, Spring http://issues.org/30-3/stuart/ (accessed 23 May 2016).

Evangelista, R. and A. Vezzani (2011), "The impact of technological and organizational innovations on employment in European firms”, Industrial and Corporate Change, Volume 21, Number 4, pp. 871899.

Firpo, S., N. M. Fortin, and T. Lemieux (2011) “Occupational Tasks and Changes in the Wage Structure”, IZA Discussion Papers, 5542.

Freeman, C., and L. Soete. 1994. “Work for All or Mass Unemployment?”, Computerised Technical Change into the Twenty-first Century. London-New York: Pinter.

Frey, C. B. and M.A. Osborne (2013) "The Future of Employment: How Susceptible are Jobs to Computerisation?”, OMS Working Papers, Oxford Martin Programme on the Impact of Future Technology.

Fuss, M. A. (1977) "The Demand for Energy in Canadian Manufacturing: An Example of the Estimation of Production Structures with Many Inputs." Journal of Econometrics, 5.1: 89-116.

Goos, M., A. Manning, and A. Salomons (2009) “Job Polarization in Europe”, American Economic Review: Papers \& Proceedings, 99:2, 58-63.

Gordon, R. J. (2012) "Is U.S. Economic Growth Over? Faltering Innovation Confronts the Six Headwinds”, CPER Insight http://www.cepr.org/sites/default/files/policy_insights/PolicyInsight63.pdf_(accessed 23 May 2016).

Gordon, R. J. (2016) The Rise and Fall of American Growth: The U.S. Standard of Living since the Civil War, Princeton Press.

Greenan, N. and D. Guellec (2000), “Technological innovation and employment reallocation”, Labour, 14(4), 547-590.

Hall, B.H., F. Lotti, and J. Mairesse (2008), "Employment, Innovation, and Productivity: Evidence from Italian Microdata.” Industrial and Corporate Change, 17: 813-39. 
Hamermesh, D. S. (1986), “The demand for labour in the long run”, in O. Ashenfelter and R. Layard (eds.), Handbook of Labor Economics, Volume 1, @Elsevier Science Publishers BV.

Hamermesh, D. S. (1991), “Labor demand: What do we know? What don’t we know?”, NBER working paper 3890.

Hamermesh, D. S. (1993), Labor Demand, Princeton University Press.

Handel, M. J. (2012) “Trends in job skill demands in OECD countries”, OECD Social, Employment and Migration Working Papers, No. 143.

Hann, Il-Horn, Siva Viswanathan, and Byungwan Koh (2011) “The Facebook App Economy” Robert H. Smith School of Business, Center for Digital Innovation, Technology and Strategy, University of Maryland.

Harrison, R., J. Jaumandreu, J. Mairesse, and B. Peters. (2008), “Does Innovation Stimulate Employment? A Firm-level Analysis Using Comparable Microdata from Four European Countries.” NBER Working Papers, 14216. Cambridge MA: NBER.

Hulten, C. R. (1990); “The Measurement of Capital”; in Berndt, Ernst R. and Jack Triplett (eds.); Fifty Years of Economic Measurement, University of Chicago Press.

Hynninen, Sanna-Mari, Jari Ojala and Jaakko Pehkonen (2013), Technological change and wage premiums: Historical evidence from linked employer-employee data, Labour Economics, vol. 24, issue $\mathrm{C}$, pages 1-11.

ICTC (2012) Employment, Investment, and Revenue in the Canadian App Economy, Information and Communications Technology Council.

Jackson, K. (1993). “The World’s First Motel Rests upon Its Memories.” Seattle Times, April 25.

Jorgenson, D. W. (1963); “Capital Theory and Investment Behaviour”; American Economic Review, Vol. 53, pp. 247-259.

Katz, R. (2012), “The Impact of Broadband on the Economy: Research to Date and Policy Issues”, ITU Broadband Series, ITU, Geneva.

Keynes, J. M. (1963) “Economic Possibilities for our Grandchildren,” in Essays in Persuasion, New York: W.W. Norton \& Co., 1963), 358-373.

Lachenmaier, S., and H. Rottmann. 2011. "Effects of Innovation on Employment: A Dynamic Panel Analysis. International Journal of Industrial Organization, 29, 210-20.

Layard, R., S. Nickell, S., and R. Jackman (1994), The Unemployment Crisis. Oxford: Oxford University Press.

Lefter, M. Alexandru and Benjamin M. Sand (2011) "Job Polarization in the U.S.: A Reassessment of the Evidence from the 1980s and 1990s”, St Gallen Economics Working Paper Series, 1103.

Machin, S., and J. Van Reenen. 1998. "Technology and Changes in Skill Structure: Evidence from Seven OECD Countries.” Quarterly Journal of Economics, 113: 1215-44. 
Mandel, M. and J. Scherer (2012) "The Geography of the App Economy”, South Mountain Economics.

Mazzolari, F. and G. Ragusa (2013). "Spillovers from High-Skill Consumption to Low-Skill Labor Markets”, Review of Economics and Statistics, 95(1), 74-86.

Michaels, G., A. Natrajz and J. Van Reenen (2014) "Has ICT Polarized Skill Demand? Evidence from Eleven Countries over 25 years”, Review of Economics and Statistics, 96 (1), 60-77.

Mokyr, J., C. Vickers and N. L. Ziebarth (2015) "The History of technological Anxiety and the Future of Economic Growth: Is this Time Different?”, Journal of Economic Perspectives, Vol. 29, N. 3. Summer 2015, pp. 31-50.

Moretti, E. (2012) “The New Geography of Jobs”, Mariner Books, Houghton Mifflin Harcourt, Boston, New York.

Nelson, R. R., and E. S. Phelps. "Investment in humans, technological diffusion, and economic growth." The American Economic Review (1966): 69-75.

Nickell, S. J., 1986, Dynamic models of labor demand, in: 0. Ashenfelter and D. Layard, eds., Handbook of Labor Economics, Vol. 2 (North Holland).

OECD. (2016a), "New Skills for The Digital Economy: Measuring the Demand and Supply of ICT Skills at Work”, OECD Digital Economy Papers, OECD Publishing, Paris (forthcoming).

OECD (2016b) “ICTS and Jobs: Complement or Substitutes? The Effects of ICT investment on Labour Demand in 19 OECD Countries", OECD Publishing, Paris (forthcoming).

OECD (2015a) The Future of Productivity, http://www.oecd.org/eco/growth/The-future-of-productivitypolicy-note-July-2015.pdf (accessed 23 May 2016).

OECD (2015b), Digital Economy Outlook 2015, OECD Publishing, Paris.

OECD (2013a), New Sources of Growth: Knowledge-based Capital - Key Analyses and Policy Conclusions - Synthesis Report. Paris, OECD

OECD (2013b). Education at a Glance 2013; OECD Indicators. OECD Publishing, 2013.

OECD (1994), The OECD Jobs Study: Facts, Analysis and Strategy. OECD Publishing, Paris.

Oliner, S., D. Sichel and K. Stiroh (2007), "Explaining a productive decade”, Brookings Papers on Economic Activity, No. 1, pp. 81-137.

Peters, B. (2004), "Employment Effects of Different Innovation Activities: Microeconometric Evidence.” ZEW Discussion Papers, 0473. Bonn, Germany: ZEW.

Rifkin, J. (1996) The End of Work: The Decline of the Global Labor Force and the Dawn of the PostMarket Era, Tarcher.

Russell, B. (1935) "In Praise of Idleness," in In Praise of Idleness and Other Essays, New York: W.W. Norton \& Co, 1935), http://www.zpub.com/notes/idle.html (accessed 23 May 2016). 
Sabadash, A. (2013), "ICT-induced Technological Progress and Employment: a Happy Marriage or a Dangerous Liaison? A Literature Review," JRC-IPTS Working Papers, JRC76143, Institute for Prospective and Technological Studies, Joint Research Centre.

Schreyer, P., P. Bignon and J. Dupont (2003), “OECD Capital Services Estimates: Methodology and a First Set of Results”, OECD Statistics Working Papers, 2003/06, OECD Publishing. http://dx.doi.org/10.1787/658687860232

Schreyer, P. (2001); “Computer price indices and international growth comparisons”, Economics of Innovation and New Technology, Vol. 10.

Schreyer, P. (2010), "Measuring Multi-Factor Productivity when Rates of Return Are exogenous," Chapter 2, pp. 13-40 in W.E. Diewert, B.M. Balk, D. Fixler, K.J. Fox and A.O. Nakamura (eds.), Price and Productivity Measurement: Volume 6 -- Index Number Theory. Trafford Press.

Severgnini, B. (2009), “Growth Accounting, ICT and Labour Demand”, in Burda M. (ed.), The Impact of ICT on Employment, Humbold-Universitat zu Berlin.

Spiezia, V. and M. Vivarelli (2002), "What Do We Know About the Effects of Information and Communication Technologies on Employment Levels?” in Greenan, N., L’Horty, Y., and Mairesse, J. (Eds.), Productivity, Inequality, and the Digital Economy - A Transatlantic Perspective, MIT Press, Cambridge, Mass.

Spitz-Oener, A. (2006) “Technical Change, Job Tasks and Rising Educational Demand: Looking Outside the Wage Structure”, Journal of Labor Economics, 24(2):235-70.

Timmer, M., et al. The world input-output database (WIOD): contents, sources and methods. No. 20120401. Institue for International and Development Economics, 2012.

Van Reenen, J. (2011), “Wage Inequality, Technology and Trade: 21st Century Evidence”, Labour Economics, 18 (6). 730-741. ISSN 0927-5371.

Zellner, A. "An Efficient Method of Estimating Seemingly Unrelated Regressions and Tests for Aggregation Bias." Journal of the American statistical Association 57.298 (1962): 348-368. 
ANNEX

Table A1. Country-specific phases of the business cycle

\begin{tabular}{lccc}
\hline Country & Before 2001 & Between crises & After 2007 \\
\hline Australia & $1990-2000$ & $2001-2006$ & $2007-2011$ \\
Austria & $1997-2000$ & $2001-2008$ & $2009-2012$ \\
Belgium & $1997-2001$ & $2002-2006$ & $2007-2012$ \\
Canada & $1992-2001$ & $2002-2007$ & $2008-2012$ \\
Denmark & $1999-2001$ & $2002-2008$ & $2009-2011$ \\
Finland & $1992-2000$ & $2001-2007$ & $2008-2012$ \\
France & $1992-2001$ & $2002-1007$ & $2008-2012$ \\
Germany & $1992-2002$ & $2003-2007$ & $2008-2012$ \\
Ireland & $1999-2003$ & $2004-2010$ & $2010-2012$ \\
Italy & $1992-2001$ & $2002-2007$ & $2008-2012$ \\
Japan & $1997-2000$ & $2001-2007$ & $2008-2012$ \\
Korea & $n \cdot a$. & $2004-2007$ & $2008-2012$ \\
Netherlands & $1997-2001$ & $2002-2007$ & $2008-2012$ \\
New Zealand & $1992-2001$ & $2002-2007$ & $2008-2012$ \\
Portugal & $1997-2001$ & $2002-2007$ & $2008-2012$ \\
Spain & $1997-2001$ & $2002-2007$ & $2008-2012$ \\
Sweden & $1995-2000$ & $2001-2007$ & $2008-2012$ \\
United Kingdom & $1996-2001$ & $2002-2007$ & $2008-2011$ \\
United States & $1992-2001$ & $2002-2007$ & $2008-2012$ \\
\hline
\end{tabular}




\section{DETAILS ON DATA}

\section{Wages by skill}

Hours worked by educational attainments are classified into three categories of skills:

- $\quad$ Low skill = 1 in ISCED 97 (= 9 ISCO 08);

- $\quad$ Medium skill $=2+3+4$ in ISCED 97 (= 2 ISCO 08);

- High skill $=5 a+5 b+6$ in ISCED 97 (= $3+4$ ISCO 08).

Figure A1 shows the resulting hourly wages by skill level, a key variable in the empirical analysis, as obtained by harmonising data from the different data sources. As expected, high skill wages are the highest and low skill wages the lowest. All series trend upward, at least until 2007, after which they either slow down or decline. In several European countries, high and medium skill wages fall between 2000 and 2005. Potential explanations for these trends include the rise of Chinese manufacturing and the burst of the dotcom bubble. 


\section{Figure A1. Hourly wages by skill}

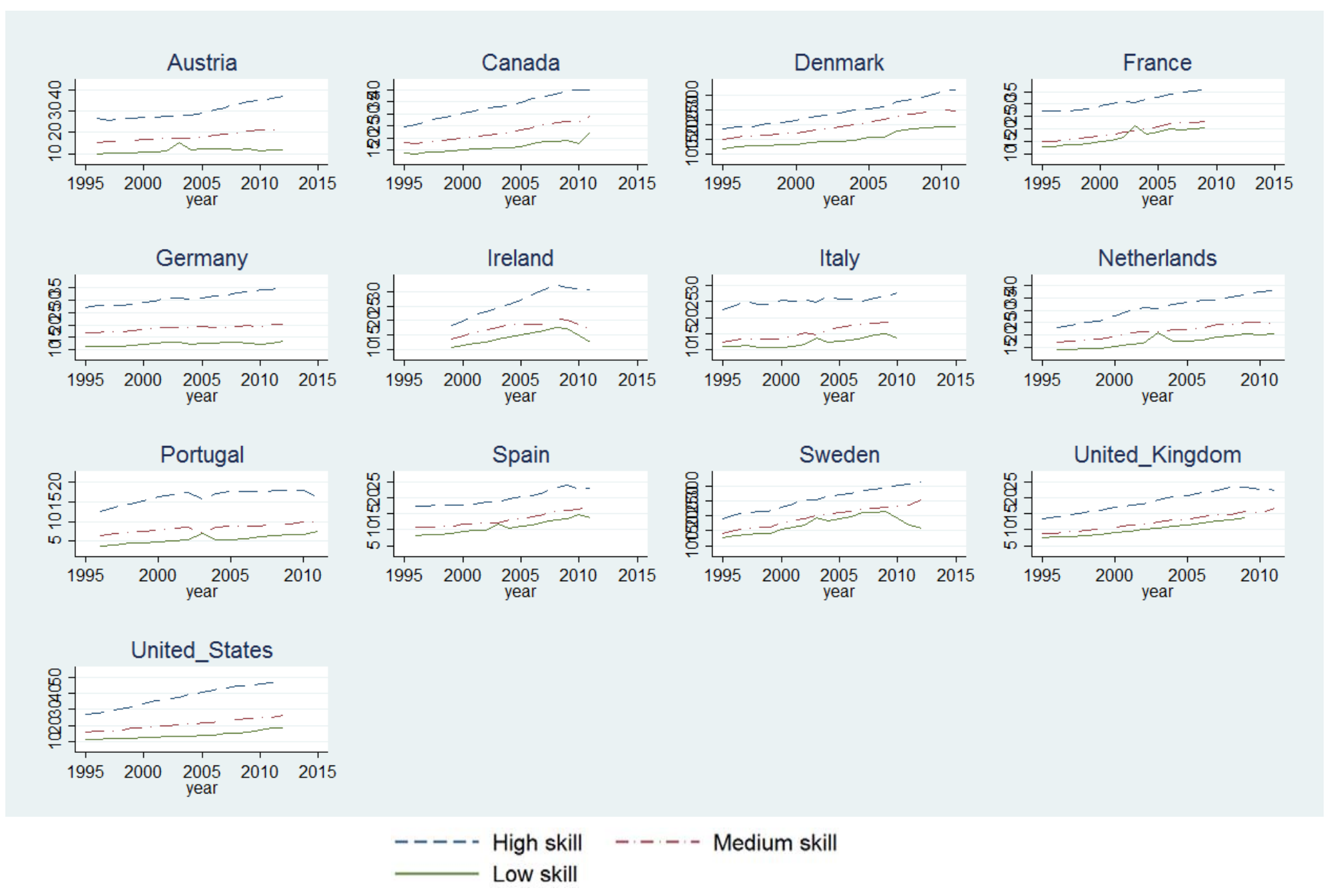




\section{Capital: stock and user cost}

Capital inputs are measured as capital services: for any given type of asset, there is a flow of productive services from the cumulative stock of past investments. Estimates of capital services in the OECD Productivity Databases are based on the perpetual inventory method (PIM). The PIM calculations are carried out by the OECD, using an assumption of common service lives for given assets for all countries, and by correcting for differences in the national deflators used for hardware, communications equipment and software assets (Schreyer, 2001, Schreyer et al., 2003). The "harmonised" deflators assume that the ratios between ICT and non-ICT asset prices evolve in a similar manner across countries, using the United States as the benchmark.

Capital service flows in the PDB relate to non-residential fixed capital only and have been computed at the level of the total economy for 19 OECD countries. They can be broken down by seven types of assets: hardware and office machinery; communication equipment; other machinery and equipment; transport equipment; non-residential construction; software; and other products.

The price of ICT capital services is the most important information for the purpose of this paper. In general, the price of capital services is measured as their rental price. If there were complete markets for capital services, rental prices could be directly observed. This is, however, not the case for many capital goods that are owned and for which rental prices have to be imputed. The implicit rent that capital good owners 'pay' themselves is defined as user costs of capital.

Total payments for capital services are then the product of the user costs for each asset and the quantity of capital services for each asset and vintage. Call $u k_{t, s}^{i}$ the price of capital services that are derived from an s-year old capital good of type $i$ in year $t$, and call $K_{t, s}^{i}$ the quantity of capital services associated with an s-year old asset. Total payments for capital services are given by expression 1 . They are expressed in current prices but for convenience it is assumed that these current price payments can be broken up into a price component $u k_{t}^{i}$ and a quantity component

$$
u k_{t}^{i} K_{t}^{i}=\sum_{s=0}^{T} u k_{t, s}^{i} K_{t, s}^{i}
$$

where $T$ indicates the maximum service life of capital asset $i$.

Typically, neither the flow of capital services nor its market prices are directly observable. The assumption is thus made that the flow of capital services from an s-year old asset is in proportion to the volume of investment of that asset $s$ years ago. Let $\lambda_{t}^{i}$ be the proportionality factor by which capital service flows and vintage investment are linked. The quantity of investment of asset $i$ in year $t, I_{t}^{i}$, is either measured in physical units if a truly homogenous asset can be observed or is obtained as the deflated value of current price investment. For this and other purposes, let $q_{t, s}^{i}$ be the price index for an s-year old asset of type $i$ prevailing in year $t$. Further, let $F_{s}$ describe the retirement pattern that describes how assets are withdrawn from service (scrapped, discarded). $F_{s}$ is non-negative and falling as $s$, the age of an asset, increases. For a new asset with $s=0, F_{0}$ takes a value of 1 . It is also assumed that the investment goods purchased and installed in period $t$ give rise to a flow of capital services in the following period. The flow of capital services is then approximated by:

$$
K_{t, s}^{i}=\lambda_{t}^{i} F_{s}^{i} I_{t-s-1}^{i}
$$

Combining expressions 1 and 2 yields:

$$
u k_{t}^{i} K_{t}^{i}=\sum_{s=0}^{T} u k_{t, s}^{i} \lambda_{t}^{i} F_{s}^{i} I_{t, s-1}^{i}
$$


where $u k_{t, s}^{i}$ has been defined as the price of one unit of capital services. More frequently, the user cost $u_{t, s}^{i}$ is defined as the cost of using one unit of vintage investment, i.e. $u_{t, s}^{i}=\lambda_{t}^{i} u k_{t, s}^{i}$.

Next, a behavioural relationship has to be introduced (Hulten 1990): a rational, cost-minimising producer will choose a vintage composition such that the relative productivity of different vintages is just equal to the relative user costs of the two vintages. The relative marginal productivity of two vintages of the same type of assets is captured by the age-efficiency function. It reflects the loss in productive capacity of a capital good over time or the rate at which the physical contributions of a capital good to production decline over time, as a result of wear and tear, and technical obsolescence. For the purpose at hand, the age-efficiency function is called $h_{s}^{i}$, with non-negative values that decline with rising age $s: h_{s}^{i}=1$ for a new capital good $(s=0)$ and $h_{s}^{i}=0$ for a capital good that has reached its maximum service life $(s=T)$. For the empirical implementation, it is assumed that the age-efficiency function is hyperbolically shaped. In a functioning market, the following relationship holds: $\left(h_{s}^{i} / h_{0}^{i}\right)=\left(u_{t, s}^{i} / u_{t, 0}^{i}\right)$. When this term is inserted into 3, one obtains:

$$
u k_{t}^{i} K_{t}^{i}=u_{t, 0}^{i}\left(\sum_{s=0}^{T} h_{s}^{i} F_{s}^{i} I_{t, s-1}^{i}\right)
$$

As a last step, we define the productive stock of asset $i$ at the end of period $t-1$ as:

$$
S_{t}^{i}=\left(\sum_{s=0}^{T} h_{s}^{i} F_{S}^{i} I_{t, S-1}^{i}\right)
$$

Equation 5 is an expression of the perpetual inventory method (PIM) that yields a measure of the productive stock of asset $\mathrm{i}$. The productive stock of asset $i$ is the sum of all vintage investment in this type of asset, corrected for the probability of retirement, and corrected for its loss in productive capacity, so that $S_{t}^{i}$ is expressed in "new equivalent" units of year $t$. Such additive aggregation across vintages implies perfect substitutability between investment goods of different vintages.

Inserting 4 into 5 yields:

$$
u k_{t}^{i} K_{t}^{i}=u_{t, 0}^{i} S_{t-1}^{i}
$$

i.e. the value of capital services at current prices is equal to the volume of the productive stock in "new equivalent" units, valued at user costs of a new capital good.

It is worth noticing that, unlike in other databases, e.g. EUKLEMS, the user cost of capital is not estimated by imposing the equality between capital remuneration and gross operating surplus (value added minus total wages) but it is based on firms' expectations about future capital productivity. Furthermore, this approach does not require perfect competition in the product market nor constant returns to scale in production (Schreyer, 2010).

Keeping aside more technical issues, two theoretical assumptions are crucial to the estimation of user costs. First, in a fully functioning asset market, the purchase price of an asset will equal the discounted flow of the value of services that the asset is expected to generate in the future (Jorgenson, 1963). Second, a rational, cost-minimising producer will choose a vintage composition such that the relative productivity of different vintages is just equal to the relative user costs of the two vintages (Hulten, 1990).

It follows from these two assumptions that technical progress embodied in new, more efficient ICT capital would be "measured" by a decrease in their user cost. This feature provides the rational for assessing the employment effects of ICTs by looking at the impact of ICT user costs on labour demand. 
Changes in ICT user costs do not simply reflect improvements in technology but they also depend on firms' expectations about the future value of ICT capital services. Therefore, for a given ICT technological trend, country differences in the factors that affect these expectations, e.g. competition, regulation, cost of borrowing, consumer preferences, market size, etc. may affect the expected value of ICT capital services and the evolution of user costs.

\section{Data by sector}

This part of the paper uses data for 10 sectors in 18 countries. Time coverage varies by country, but in general figures for 1995-2011 are available (see Table A2). Nominal figures for the energy sector were calculated by subtracting the manufacturing sector from the B-E aggregate; value added in volumes for this sector were calculated by first recalculating the deflator. Real estate activities are not considered in this study due to the difficulties in constructing consistent input and output measures for this sector: that is, capital services data typically exclude residential construction, whereas value added figures include all real estate activities.

A higher level of industry detail would severely limit the geographical coverage of the sample. The countries in the sample comprise all countries available in the OECD Productivity Database. Canada and Switzerland could not be included due to a lack of (recent) data on hours worked or (volumes of) value added.

Table A2. Coverage of industry data

\begin{tabular}{llll}
\hline & $\begin{array}{c}\text { first } \\
\text { year }\end{array}$ & $\begin{array}{c}\text { last } \\
\text { year }\end{array}$ & industries not available \\
\hline Australia & 1995 & 2011 & \\
Austria & 1995 & 2012 & \\
Belgium & 1995 & 2012 & \\
Germany & 1995 & 2012 & \\
Denmark & 1995 & 2012 & \\
Spain & 1995 & 2012 & energy; manufacturing \\
Finland & 1995 & 2012 & \\
France & 1995 & 2012 & \\
United Kingdom & 1995 & 2012 & \\
Ireland & 1998 & 2012 & \\
Italy & 1995 & 2012 & \\
Japan & 1995 & 2012 & energy; $\quad$ manufacturing; \\
& & & government and care; culture, recreation and other \\
& & & services \\
Korea & 2004 & 2012 & \\
Netherlands & 1995 & 2012 & \\
New Zealand & 2009 & 2011 & energy; culture, recreation and other services \\
Portugal & 1995 & 2011 & \\
Sweden & 1995 & 2012 & \\
United States & 1998 & 2012 & \\
\hline
\end{tabular}

\section{STAN Database}

The main source of data is the OECD database for Structural Analysis (STAN). Information on value added (at factor cost), labour cost, and hours worked is sourced from this database. The most recent release of the ISIC Rev. 4 version is the default source. When a specific country/industry/year combination is not 
available, the data were supplemented with the provisional 2013 version. Finally, for combinations that are not available from either version of the STAN, the data are supplemented with the Annual National Accounts database.

\section{Annual National Accounts database}

Data from the Annual National Accounts (ANA) database supplement the STAN data when missing. Volumes from STAN were rebased from 2005 to the current OECD reference year 2010. Moreover, information on the level of gross fixed assets (GFA) by sector is taken from this database, which are used to obtain a sector level estimate of total capital services (see Variables).

\section{Productivity Database}

The Productivity Database provides data at the total economy level on labour and multifactor productivity levels and growth, as well as the growth accounting contributions of labour and capital services. The underlying calculations (explained above under 'Capital: stocks and user cost') involve the estimation of productive capital stocks, and allow the calculation of unit user cost by type of capital, i.e. the cost of capital services by unit of (productive) capital. These costs are used to determine the relative price of ICT and non-ICT capital with respect to labour.

The total economy values for the productive capital stocks are used together with the GFA data from the ANA database to obtain an estimate of the productive capital stock by sector (see Variables).

\section{Dutch growth accounts}

The Dutch growth accounts provide data by sector on multifactor productivity growth, and factor contributions for the Netherlands. The methodology is consistent with the OECD Productivity Database in the sense that an ex-ante rate of return is assumed to derive the cost of capital. The underlying calculations involve the derivation of productive capital by sector and asset type. This information is used to derive the share of ICT in total capital services by sector in all countries (see Variables).

\section{Export data}

Data on export values are taken from the Trade in Value Added (TiVA) database. Volumes are obtained by deflating with the output price index by sector. It was recoded to ISIC Rev. 4 using a key based on production weights, constructed by combining the STAN ISIC Rev. 3 tables with the ones for ISIC Rev. 4. For years not available in the TiVA database, the export shares are interpolated based on a linear regression. For countries not in the STAN ISIC Rev. 4 database, the average for the available countries is assumed. 
Table A2. Variables in the analysis by industry

Value added

Hours worked

Labour cost per hour

User cost of ICT capital

User cost of non-ICT capital

Domestic demand

Export

Total income

Share of ICT capital in total $s^{I^{T}}$ production

Share of monopolistic rents
VA At factor cost (excludes taxes and subsidies). To obtain the volumes (base year 2010), the deflator of value added at market basic prices is used. It is available directly from STAN; in case it is not, and NA data are used, it is calculated as value added minus the balance of taxes and subsidies, or total labour cost plus the gross operating surplus and mixed income.

H Total hours worked (employees plus self-employed)

w Total labour compensation of employees (including social and other contributions) divided by hours worked by employees. It is assumed that the hourly remuneration of self-employed is the same.

$u^{I T} \quad$ Unit cost of ICT capital services: ICT capital services divided by productive ICT capital stock. Assumed to be equal across sectors.

$u^{N I T} \quad$ Unit cost of non-ICT capital services: non-ICT capital services divided by productive non-ICT capital stock. Assumed to be equal across sectors.

DD Gross output minus the value of total exports

$X \quad$ Total value of exports

GDP Gross domestic product

See below.

Obtained as

$$
m_{j c t}=1-\frac{1}{\mu_{j c t}}
$$

where $\mu_{j c t}$ is the industry markup. It is determined as

$\mu_{j c t}=V A_{j c t} / C_{j c t} \cong \mu_{c t} \times\left(\mu_{j t, N L} / \mu_{t, N L}^{*}\right)$,

where $C$ is total cost of production, and

$\mu_{t, N L}^{*}=\sum_{j}\left(\mu_{j t, N L} \times V A_{j t, N L} / V A_{t, N L}\right)$

Thus, the country-level markup $\mu_{c t}$ is combined with information on the markup by industry from the Netherlands, taking into account differences in industry structure through value added shares.

Share of ICT capital in total cost of production

The capital cost of ICT is approximated by

$$
u_{c t}^{I T} K_{j c t}^{I T}=u_{c t}^{I T} \frac{K_{j t, N L}^{I T}}{K_{t, N L}} \frac{G F A_{j c t}}{G F A_{c t}} K_{c t}
$$


for industry $j$, country $c$, year $t$. Thus, total productive capital stock $K_{c t}$ is distributed across industries according the industry shares in Gross Fixed Assets $G F A_{j c t} / G F A_{c t}$. This gives an estimate of productive capital by industry. To be consistent with country-level information about the ICT productive capital the figures are scaled in such a way that the sum over industries equals the observed total economy value. Next the productive capital stock is split into an ICT and non-ICT component, using the observed ratio in the Netherlands $K_{j t, N L}^{I T} / K_{t, N L}$. Finally, it is multiplied by using the country-specific unit user cost of ICT to derive the cost of the capital services. Capital costs of non-ICT are calculated equivalently.

The information on the ratio $G F A_{j c t} / G F A_{c t}$ has been extrapolated and imputed in countries where 1 . Not the whole time-series was available, and 2. Not all industries were available. In the first case, the country-industry average was calculated, and this information was used to extrapolate the time-series controlling for a time-trend. In the second case, the share of the industries missing in a particular country was distributed according to the average relative industry shares in the other countries.

The procedure provides estimates of $s_{j c t}^{I T}$ for 11 countries (Australia, Austria, Belgium, Germany, Denmark, Finland, France, UK, Italy, Korea, Netherlands), and similarly for non-ICT. For the remaining countries, with no information on Gross Fixed Assets at all, the share of ICT is derived as follows. Using the estimates of total capital services and the total labour cost, it is possible to calculate the share in labour cost. This share is regressed against the share in value added, allowing the coefficient to differ by industry and controlling for year effects. This allows to make an out-of-sample forecast of the labour share, for countries that have the share in value added available but not the share in cost. For Japan and USA, hours worked is observed only for employees, therefore the share of total labour cost in value added is first estimated by regressing it against the share of labour cost for employees for those countries where both are available, and then making the out-of-sample prediction. The labour shares implies the share of total capital, and finally the ICT share in total cost of production is obtained by applying the average share in total capital services of the 11 countries for which it was estimated in the first step. 


\section{METHODOLOGY}

This paper analyses the effects of ICTs on employment within the standard labour demand theory. Such a framework has the advantage to model the employment effects of ICTs as a result of firms' decisions and market mechanisms rather than as a technology-driven outcome.

Fast technological progress in ICTs has led to a rapid decrease in the price of ICT equipment and software and to large investments in ICTs. Such investment have resulted into changes in the production mix of labour, ICT capital and other types of capital, on the one hand, and into a decrease in production costs and an increase in final demand, via lower prices and/or higher income, on the other.

The net impact of technological progress embodied in ICT capital on labour demand depends, therefore, on: $i$ ) the extent to which ICT capital substitutes for labour (partial elasticity of substitution); and ii) the extent to which lower unit costs generate higher demand and production via a decrease in prices (price elasticity) and/or an increase in income (income elasticity).

Consider a firm using three factors of production: labour (H), ICT capital (IT) and non-ICT capital (K). Holding output and other input prices constant, cost minimisation implies that (Hamermesh, 1986):

$$
\text { 1. } \frac{\partial \ln H}{\partial \ln w_{I T}}=c_{I T} \sigma_{H, I T}
$$

where $w_{I T}$ is the user cost of ICT capital, $c_{I T}$ the cost share of ICT capital and $\sigma_{H, I T}$ the partial elasticity of substitution between labour and ICT capital (the time subscript is omitted for sake of clarity). The latter measures the percentage change in the labour-ICT capital ratio from a change in the wage-ICT user cost ratio, holding output and other input prices constant.

Equation 1 states that, following a 1\%-decrease in the user cost of ICT, firms reduce labour per unit of output by $c_{I T} \sigma_{H, I T}$ per cent. This reflects the substitution effect along an isoquant, i.e.: at a constant output.

When the ICT user cost decreases, unit costs of production (c) decrease as well by:

$$
\text { 2. } \frac{\partial \ln c}{\partial \ln w_{I T}}=c_{I T}
$$

Depending on the degree of competition in the product market, part of the decrease in unit costs would be translated into lower product prices, part into higher monopolistic rents. Under perfect competition, the decrease in unit cost is fully translated into a decrease in price $\left(\partial \ln p^{C}\right)$ :

$$
\text { 3. } \frac{\partial \ln p^{C}}{\partial \ln w_{I T}}=\frac{\partial \ln c}{\partial \ln w_{I T}}=c_{I T}
$$

Under imperfect competition, the decrease in price $\left(\partial \ln p^{M}\right)$ following a decrease in ICT user costs is:

4. $\frac{\partial \ln p^{M}}{\partial \ln w_{I T}}=\left(1-s_{M}\right) \frac{\partial \ln c}{\partial \ln w_{I T}}=\left(1-s_{M}\right) c_{I T}$

where $s_{M}$ is the share of monopolistic rents in total value added. The increase in monopolistic rents per unit of output from a decrease in ICT user costs is therefore: 
5. $\frac{\partial \ln c}{\partial \ln w_{I T}}-\frac{\partial \ln p^{M}}{\partial \ln w_{I T}}=-S_{M} c_{I T}$

Lower prices and higher income (i.e. monopolistic rents) would raise final demand and output (scale effect). The increase in output would then depend on the cost share of ICT capital $\left(c_{I T}\right)$ as well as the elasticity of final demand to prices $(\varepsilon)$ and to income $(\eta)$.

The total effect on employment, i.e. substitution effect plus scale effect, is therefore:

6. $\frac{\partial \ln H}{\partial \ln w_{I T}}=c_{I T} \sigma_{H, I T}-\varepsilon\left(1-s_{M}\right) c_{I T}+\eta\left(-S_{M} c_{I T}\right)$

Total economy and breakdown by skill levels

For the total economy, the economic theory predicts that both the price elasticity $(\varepsilon)$ and the income elasticity $(\eta)$ of final demand are equal to one. Indeed, any decrease in the output price raises real income, thus leading to a proportional increase in real consumption and/or savings. Similarly, any increase in extraprofits raise nominal income, consumption and/or savings by the same proportion. By accounting identity, savings equals (domestic plus foreign) investments. Therefore, any decrease in the output price and any increase in income would translate into an equal increase in final demand (consumption plus investments). ${ }^{1}$

Therefore, for the total economy, equation 6 simplifies to:

$$
\text { 7. } \frac{\partial \ln H}{\partial \ln w_{I T}}=c_{I T}\left(\sigma_{H, I T}-1\right) .
$$

It follows that ICT investments increase or reduce labour demand depending on whether the elasticity of substitution between labour and ICT capital is smaller or bigger than one. The main aim of this study is, therefore, to estimate the value of the partial elasticity of substitution between labour and ICT capital, $\sigma_{H, I T}$.

Clearly, the same logic applies when disaggregating employment by skill level. All the results emphasized above hold for skill-specific versions of equation 7. To obtain expressions for skill-specific elasticities of substitutions, can be used a skill-augmented version of a translog cost function,

$$
\text { 8. } \quad \ln C=\ln Y+a_{0}+\sum_{i} a_{i} \ln w_{i}+\frac{1}{2} \sum_{i, j} b_{i, j} \ln w_{i} \ln w_{j} \quad\left(i, j=h, m, l, k_{i c t}, k_{n i c t}\right)
$$

where $w$ represents the price of each factor, and $h, m, l$ indicate high, medium, and low skills. Denoting with $X_{i}$ the demand for each factor, Shephard's Lemma states that

$$
\text { 9. } \quad \frac{\partial \ln C}{\partial \ln w_{i}}=\frac{\partial C}{\partial w_{i}} \frac{w_{i}}{C}=\frac{X_{i} w_{i}}{C}=a_{i}+\sum_{j} b_{i, j} \ln w_{j}
$$

The cross-price elasticity of factor $i$ 's demand can be expressed as

$$
\varepsilon_{i j}=c_{j} \sigma_{i j}
$$

Where $\sigma_{h, i c t}, \sigma_{m, i c t}$ and $\sigma_{l, i c t}$ are the partial elasticities of substitution between ICT capital and each of the three categories of labor, and $c_{j}$ is the cost share of factor $j$.

To obtain the elasticities, we need to estimate the coefficients $b_{h, i c t}, b_{m, i c t}, b_{l, i c t}$ in equation 9 and apply the formula 


$$
\sigma_{i j}=\frac{\partial \ln \left(\frac{X_{i}}{X_{j}}\right)}{\partial \ln \left(\frac{w_{j}}{w_{i}}\right)}=1+\frac{b_{i j}}{s_{i} s_{j}}
$$

Notice that having $b_{i j}=0$ would imply a unit elasticity of substitution between the two factors, corresponding to the Cobb-Douglas case. At the same time $\sigma_{i j}<1$ implies that the two factors are gross complements, while $\sigma_{i j}>1$ that they are gross substitutes. Notice that with more than two production factors, it can be the case that $\varepsilon_{i j}<0$, requiring $\sigma_{i j}<0$ as the shares $c_{i}$ are always non-negative.

This approach accounts for the employment effects of technological progress embodied in ICT capital goods but it does not consider disembodied technical change. The latter has effects both on the substitution between labour and ICT capital, on the one hand, and on the decrease in output price, on the other.

First, as discussed in the section 2, disembodied technical change reduces the demand for labour per unit of output if it is labour-saving. Therefore, estimates based on embodied technical progress only may underrate the negative impact of ICT on employment. Second, disembodied technical progress raises multifactor productivity (MFP) thus reducing unit cost and output prices. Not accounting for disembodied technical change may, therefore, underestimate the positive effects of ICTs on final demand and employment.

While it is hard to quantify disembodied technical progress due to ICTs, two considerations suggest that the above measurement errors may not be large. First, there is growing evidence that: i) a significant part of MFP is associated with investment in intangible assets (OECD, 2013a) and ii) for ICT capital to raise productivity, it requires complementary investments in intangible assets (Corrado et al., 2014). Therefore, ICT investments are strongly correlated to intangible assets and are likely to capture a significant proportion of disembodied technical progress due to ICTs.

Second, firms' expectations about the future value of ICT capital services would also reflect productivity increases due to disembodied technical progress stemming from ICTs. As discussed in the following section, such expectations are reflected in ICT capital user costs and in the investment decisions by firms. Therefore, to the extent that firms anticipate the productivity effects of disembodied technical progress, these effects would be also be captured by the estimates provided in this paper.

The stochastic version of equation 9 is given by

10.

$$
s_{i k t}=a_{i}+\sum_{j} b_{i, j} \ln w_{j k t}+\varepsilon_{i k t}
$$

where $k$ and $t$ are respectively the country and time index. But any attempt of estimating 10 as it is would incur several problems. The first concern is the presence of unobserved fixed effects at the country level that would result in omitted variable bias, i.e. $\varepsilon_{i k t}=u_{i k}+\epsilon_{i k t}$. The simplest way to deal with this problem is to estimate the equation in differences.

In addition to removing a country specific fixed effect, differencing is useful to remove a likely unit root in the data. However, differencing might not be enough to fully account for the dynamic properties of the data, as one must recognise that equation 1 characterises long-run relationships among variables. In the medium and short-run, variables deviate from their steady state levels: changing the input mix is a slow process which requires time and resources for the firm. Typically, adjustment costs are incurred because changing the input mix is costly for the firm. 
Ignoring these adjustment lags would result in biased estimates. A test of autocorrelation of residuals applied to the demand equation for ICT capital does not allow rejecting the null hypothesis of first order autocorrelation of the residuals. ${ }^{2}$ Therefore, a first order autoregressive component is added to the differenced version equation 10, yielding

$$
\text { 10'. } \Delta s_{i k t}=\rho \Delta s_{i k t-1}+\sum_{s=0}^{2} \sum_{j} b_{i j}^{s} \ln _{j k t-s}+d+\Delta \epsilon_{i k t}
$$

In 10' prices are expressed in levels rather than differences, in order to disentangle more clearly their short and long run impact on the shares. ${ }^{3}$ The vector $d$ contains a full set of time dummies whose inclusion is useful to mitigate the possibility of cross-correlation among countries. Notice that the inclusion of a lag for the dependent variable can be rationalised by the presence of adjustment costs, but also resulting from more sophisticated models of expectation formation and price stickiness (Nickell, 1986).

Because 10' describes a system of demand equations, the exercise starts by estimating (21') within a system of four equations (all five factor demand equations minus one, which is redundant given the constraints discussed below). A natural choice of estimator is given by Zellner' Seemingly Unrelated Regression estimator (SURE, 1962). The equations are seemingly unrelated because none of the dependent variables enter the system as independent variables. Yet, being generated as a demand system it is likely that the errors from each equation are correlated. ${ }^{4}$

It can be shown that SURE provides efficiency gains over OLS only when the equations have different regressors. In this case, all equations contain exactly the same regressors and therefore SURE is equivalent to equation-by-equation OLS results. However, the advantage of using SURE is given by the possibility of imposing cross equations restrictions required for the standard neoclassical properties of the cost function to hold.

These restrictions are:

$$
\begin{array}{lc}
\text { 11a. } b_{i j}^{S}=b_{j i}^{S} & \forall i, j, s \\
\text { 11b. } \sum_{s=0}^{2} \sum_{j} b_{i j}^{S}=0 & \forall i \\
\text { 11c. } b_{i j}^{1}=-b_{i j}^{0}(1+\rho), b_{i j}^{2}=b_{i j}^{0} \rho & \forall i, j
\end{array}
$$

The drawback of this method is that it is not designed for panel data, and thus it cannot address dynamic panel bias (Nickell, 1986). Using GMM-type estimators is problematic in this context given the relatively low number of observations. ${ }^{5}$

For the total economy, the labour demand regression has been estimated as a single equation, leaving out the other factor demand equations in the system using GMM techniques to control for endogeneity and unobserved heterogeneity. The analysis by skill level requires the estimation of a demand equation for each group of workers, and therefore the system approach was adopted.

Table A3 presents the total economy results. A second lag is introduced, since the correlation in the dependent variable appears to be of a second order. These results are used to construct the employment growth due to changes in ICT cost in Figure 8 of the main text. The estimation was done with no restrictions imposed on the coefficients; testing the relevant restrictions ex-post however shows that they cannot be rejected. Moreover, the long-run coefficients are all not significantly different from zero. 
Table A3. Estimation results for total economy labour demand equation

$\begin{array}{lr}\text { Dependent variable } w H / C & \\ t-1 & 1.388^{* * *} \\ t-2 & -0.472^{* * *}\end{array}$

Hourly wage

$\begin{array}{lr}t & 0.073^{* * *} \\ t-1 & -0.125^{* * *} \\ t-2 & 0.058^{* * *}\end{array}$

Relative price ICT

$\begin{array}{lr}t & -0.055^{* *} \\ t-1 & 0.054^{* *}\end{array}$

Relative price non-ICT

\begin{tabular}{|c|c|c|}
\hline$t$ & -0.116 & *** \\
\hline$t-1$ & 0.156 & *** \\
\hline$t-2$ & -0.060 & **** \\
\hline constant & 0.002 & *** \\
\hline$N$ & 332 & \\
\hline Significance of & tests at 5 & $5 \%$ \\
\hline Sargan-Hansen & no & \\
\hline $1^{\text {st }}$ order AC & yes & \\
\hline $2^{\text {nd }}$ order AC & no & \\
\hline
\end{tabular}

$*^{* *},{ }^{* * *}$ means significant at $1 \%, \frac{2}{5 \%, 10 \% \text { level. }}$

Estimation method is SYS-GMM (Blundell and Bond, 1998) using lags $t$-2 and further back as instruments. All regressions include year and country dummies.

The results of estimating system 10' imposing constraints 11a-c, are presented in Table A4a. The estimates seem to point toward a very similar relation of all categories of labour with ICT capital. However, the main problems with the results of this specification are the large standard errors associated with the coefficients of the various kinds of labour. In particular, these results are at odds with the aggregate model in which contemporaneous and lagged values for the average log-wage enters highly significantly (see OECD, 2016b).

One potential explanation for such large standard errors is that of multicollinearity of the regressors, especially for labour skill levels (see Figure A1 on hourly wages by skill to appreciate a similar trend). In some cases, it might be convenient to maintain aggregate information when possible.

Fuss (1977) proposes a methodology to overcome potential multicollinearity of the regressors. It consists of estimating a labour aggregate sub-level and then in a following step the aggregate model, conditional on the estimates of the first step. This procedure is only valid under weak separability of the labour input with respect to ICT and non-ICT capital.

For this reason it is necessary to test for weak separability of labour inputs from other factors. The test is conducted for both short and long run. The results of the test indicates that in the short run, all types of 
labour are non-separable from either ICT or non-ICT capital. In the long-run, however, the null hypothesis of weak separability cannot be rejected with very substantial confidence levels.

This means that in the long run - by definition of separability - the relative skill composition of labour is independent on both ICT and non-ICT capital. In other words, ICTs can complement or substitute labour, but to an identical degree for each category of skills. In the short run, however, this is not the case.

What is needed is a specification disentangling the long and short run impact of ICTs on each type of labour. The procedure is discussed next.

Relying on separability, a long run labour aggregator of the following form is estimated

$$
H_{t}=\theta\left(H_{t}^{h}\right)^{\alpha}\left(H_{t}^{m}\right)^{\beta}\left(H_{t}^{l}\right)^{1-\alpha-\beta}
$$

It can be shown that such an aggregator provides a price index for the aggregate wage of identical form (i.e. Cobb-Douglas). Then, its parameters are estimated and plugged into 10' to perform a second estimation stage with the share of aggregate labour and the share of ICT in total cost, in which labour is disaggregated by skill. The results are presented in Table A4b.

Now the standard errors on the skill coefficients are much smaller, but they preserve the same signs of Table A4a. These coefficients represent the short run deviations from the long run equilibrium behaviour, and they are used to construct figures 7 , and 9. 
Table A4a. Estimation results for a system of demand equations.

\begin{tabular}{|c|c|c|c|c|}
\hline & (1) & (2) & (3) & (4) \\
\hline VARIABLES & high skill share & mid skill share & low skill share & ICT capital share \\
\hline high skill share (t-1) & $\begin{array}{r}0.332 * * * \\
(0.0459)\end{array}$ & & & \\
\hline mid skill share (t-1) & & $\begin{array}{r}0.316^{* * *} \\
(0.0458)\end{array}$ & & \\
\hline low skill share (t-1) & & & $\begin{array}{r}0.372 * * * \\
(0.0454)\end{array}$ & \\
\hline ICT capital share (t-1) & & & & $\begin{array}{r}0.694 * * * \\
(0.0481)\end{array}$ \\
\hline log high skill wage (t) & $\begin{array}{r}0.148 * * * \\
(0.0205)\end{array}$ & $\begin{array}{r}-0.0453^{* *} \\
(0.0180)\end{array}$ & $\begin{array}{r}-0.0557 * * * \\
(0.0100)\end{array}$ & $\begin{array}{r}-0.00760 * * * \\
(0.00256)\end{array}$ \\
\hline log high skill wage (t-1) & $\begin{array}{r}-0.242 * * * \\
(0.0314)\end{array}$ & $\begin{array}{r}0.0709 * * * \\
(0.0249)\end{array}$ & $\begin{array}{c}0.107 * * * \\
(0.0128)\end{array}$ & $\begin{array}{r}0.0156 * * * \\
(0.00406)\end{array}$ \\
\hline log high skill wage (t-2) & $\begin{array}{r}0.0907 * * * \\
(0.0240)\end{array}$ & $\begin{array}{r}-0.0185 \\
(0.0194)\end{array}$ & $\begin{array}{r}-0.0547 * * * \\
(0.0116)\end{array}$ & $\begin{array}{r}-0.00873^{* * *} \\
(0.00271)\end{array}$ \\
\hline log mid skill wage (t) & $\begin{array}{r}-0.0453 * * \\
(0.0180)\end{array}$ & $\begin{array}{r}0.115^{* * *} \\
(0.0209)\end{array}$ & $\begin{array}{r}-0.0555^{* * *} \\
(0.00949)\end{array}$ & $\begin{array}{r}-0.00396 * \\
(0.00222)\end{array}$ \\
\hline log mid skill wage (t-1) & $\begin{array}{r}0.0709 * * * \\
(0.0249)\end{array}$ & $\begin{array}{r}-0.178 * * * \\
(0.0266)\end{array}$ & $\begin{array}{r}0.0758 * * * \\
(0.0111)\end{array}$ & $\begin{array}{r}0.00444 \\
(0.00285)\end{array}$ \\
\hline log mid skill wage (t-2) & $\begin{array}{r}-0.0185 \\
(0.0194)\end{array}$ & $\begin{array}{c}0.0432 * \\
(0.0227)\end{array}$ & $\begin{array}{r}-0.00946 \\
(0.0109)\end{array}$ & $\begin{array}{r}0.000807 \\
(0.00230)\end{array}$ \\
\hline log low skill wage (t) & $\begin{array}{r}-0.0557 * * * \\
(0.0100)\end{array}$ & $\begin{array}{r}-0.0555 * * * \\
(0.00949)\end{array}$ & $\begin{array}{r}0.119 * * * \\
(0.0112)\end{array}$ & $\begin{array}{r}-0.00225^{* *} \\
(0.00108)\end{array}$ \\
\hline log low skill wage (t-1) & $\begin{array}{r}0.107^{* * *} \\
(0.0128)\end{array}$ & $\begin{array}{r}0.0758^{* * *} \\
(0.0111)\end{array}$ & $\begin{array}{r}-0.209 * * * \\
(0.0146)\end{array}$ & $\begin{array}{r}0.00497 * * * \\
(0.00131)\end{array}$ \\
\hline log low skill wage (t-2) & $\begin{array}{r}-0.0547 * * * \\
(0.0116)\end{array}$ & $\begin{array}{r}-0.00946 \\
(0.0109)\end{array}$ & $\begin{array}{r}0.0833^{* * *} \\
(0.0141)\end{array}$ & $\begin{array}{r}-0.00336 * * * \\
(0.00117)\end{array}$ \\
\hline ICT user cost (t) & $\begin{array}{r}-0.00760 * * * \\
(0.00256)\end{array}$ & $\begin{array}{r}-0.00396 * \\
(0.00222)\end{array}$ & $\begin{array}{r}-0.00225^{* *} \\
(0.00108)\end{array}$ & $\begin{array}{r}0.0391^{* * *} \\
(0.00137)\end{array}$ \\
\hline ICT user cost (t-1) & $\begin{array}{r}0.0156 * * * \\
(0.00406)\end{array}$ & $\begin{array}{r}0.00444 \\
(0.00285)\end{array}$ & $\begin{array}{r}0.00497 * * * \\
(0.00131)\end{array}$ & $\begin{array}{r}-0.0685^{* * *} \\
(0.00296)\end{array}$ \\
\hline ICT user cost (t-2) & $\begin{array}{r}-0.00873^{* * *} \\
(0.00271)\end{array}$ & $\begin{array}{c}0.000807 \\
(0.00230)\end{array}$ & $\begin{array}{r}-0.00336 * * * \\
(0.00117)\end{array}$ & $\begin{array}{r}0.0300 * * * \\
(0.00203)\end{array}$ \\
\hline capital user cost (t) & $\begin{array}{r}-0.0555 * * * \\
(0.0124)\end{array}$ & $\begin{array}{r}-0.0351 * * * \\
(0.0112)\end{array}$ & $\begin{array}{c}-0.0254^{*} \\
(0.0132)\end{array}$ & $\begin{array}{r}-0.00741 * * * \\
(0.00117)\end{array}$ \\
\hline capital user cost (t-1) & $\begin{array}{r}0.0726 * * * \\
(0.0209)\end{array}$ & $\begin{array}{r}0.0456 * * \\
(0.0189)\end{array}$ & $\begin{array}{r}0.0280 \\
(0.0222)\end{array}$ & $\begin{array}{r}0.0143^{* * *} \\
(0.00192)\end{array}$ \\
\hline capital user cost (t-2) & $\begin{array}{r}-0.0167 \\
(0.0121)\end{array}$ & $\begin{array}{r}-0.0105 \\
(0.0109)\end{array}$ & $\begin{array}{r}-0.00334 \\
(0.0126)\end{array}$ & $\begin{array}{r}-0.00745^{* * *} \\
(0.00116)\end{array}$ \\
\hline Observations & 177 & 177 & 177 & 177 \\
\hline R-squared & 0.599 & 0.619 & 0.702 & 0.893 \\
\hline
\end{tabular}


Table A4b. Estimation results for a two equations system obtained imposing long run separability

\begin{tabular}{|c|c|c|}
\hline VARIABLES & $\begin{array}{r}(1) \\
\text { aggregate wage share }\end{array}$ & $\begin{array}{r}(2) \\
\text { ICT capital share }\end{array}$ \\
\hline ICT capital share (t-1) & & $\begin{array}{r}0.695 * * * \\
(0.0494)\end{array}$ \\
\hline aggregate wage share (t-1) & $\begin{array}{r}0.756 * * * \\
(0.0601)\end{array}$ & \\
\hline log high skill wage (t) & & $\begin{array}{r}-0.00617 * * * \\
(0.00187)\end{array}$ \\
\hline log high skill wage (t-1) & & $\begin{array}{r}0.0180 * * * \\
(0.00309)\end{array}$ \\
\hline log high skill wage (t-2) & & $\begin{array}{r}-0.0121^{* * *} \\
(0.00189)\end{array}$ \\
\hline log mid skill wage (t) & & $\begin{array}{r}-0.0135^{* * * *} \\
(0.00193)\end{array}$ \\
\hline log mid skill wage (t-1) & & $\begin{array}{r}0.0201^{* * *} \\
(0.00314)\end{array}$ \\
\hline log mid skill wage (t-2) & & $\begin{array}{r}-0.00671^{* * *} \\
(0.00200)\end{array}$ \\
\hline log low skill wage (t) & & $\begin{array}{r}-0.00676^{* * *} \\
(0.00146)\end{array}$ \\
\hline log low skill wage (t-1) & & $\begin{array}{r}0.0130 * * * \\
(0.00214)\end{array}$ \\
\hline log low skill wage (t-2) & & $\begin{array}{r}-0.00619 * * * \\
(0.00149) \\
\end{array}$ \\
\hline ICT user cost (t) & $\begin{array}{r}-0.0265 * * * \\
(0.00408)\end{array}$ & $\begin{array}{r}0.0403^{* * *} \\
(0.00138)\end{array}$ \\
\hline ICT user cost (t-1) & $\begin{array}{r}0.0510 * * * \\
(0.00630)\end{array}$ & $\begin{array}{r}-0.0707^{* * *} \\
(0.00294)\end{array}$ \\
\hline ICT user cost (t-2) & $\begin{array}{r}-0.0250 * * * \\
(0.00401)\end{array}$ & $\begin{array}{r}0.0310 * * * \\
(0.00201)\end{array}$ \\
\hline capital user cost (t) & $\begin{array}{r}-0.116^{* * *} \\
(0.00443)\end{array}$ & $\begin{array}{r}-0.00618 * * * \\
(0.00123)\end{array}$ \\
\hline capital user cost (t-1) & $\begin{array}{r}0.197 * * * \\
(0.0103)\end{array}$ & $\begin{array}{r}0.0134^{* * *} \\
(0.00200)\end{array}$ \\
\hline capital user cost (t-2) & $\begin{array}{r}-0.0806 * * * \\
(0.00822)\end{array}$ & $\begin{array}{r}-0.00739 * * * \\
(0.00115)\end{array}$ \\
\hline aggregate wage (t) & $\begin{array}{r}0.0890 * * * \\
(0.0126)\end{array}$ & \\
\hline aggregate wage (t-1) & $\begin{array}{r}-0.193^{* * *} \\
(0.0205)\end{array}$ & \\
\hline aggregate wage (t-2) & $\begin{array}{r}0.105^{* * * *} \\
(0.0125)\end{array}$ & \\
\hline Observations & 169 & 169 \\
\hline R-squared & 0.946 & 0.906 \\
\hline
\end{tabular}

Nb. Share variables are in difference. 


\section{Sector-specific analysis}

Unlike the analysis for the total economy and by skill-level, the analysis by sector uses a Generalized Leontief production function. As the translog specification, it allows the elasticity of substitution to vary over time, sectors, and across countries and contains the Cobb-Douglas and the CES function as special cases. A further advantage of this approach is that labour demand can be estimated based on unit input costs only and does not require the cost shares of each input (such as in the translog function). This is clearly a big advantage as our dataset does not contain information on the sector-levels stocks of ICT and non-ICT capital. ${ }^{6}$

Cost minimisation for a Generalized Leontief production function requires that (Hamermesh, 1993) omitting the country subscript for convenience:

12. $\frac{H_{j t}}{V A_{j t}}=a_{j}^{L}+a_{j}^{I T}\left[\frac{u_{j t}^{I T}}{w_{j t}}\right]^{\frac{1}{2}}+a_{j}^{N I T}\left[\frac{u_{j t}^{N I T}}{w_{j t}}\right]^{\frac{1}{2}}$

Value added captures the volume of output here and is therefore expressed in constant (2010) prices. The $a_{L, X}$ parameters are the technical coefficients of the production function. To avoid issues of comparability across countries, all variables are scaled with the averages by country-industry. is:

The partial elasticity of substitution between labour and ICT capital in the Generalized Leontief case

13. $\sigma_{j c t}^{H, I T}=\frac{a_{j}^{I T} \sqrt{u_{c t}^{I T} w_{j c t}}}{2 s_{j c t}^{I T} s_{j c t}^{L}}$

and equivalently for non-ICT capital. Note that these elasticities vary across countries, industries and time, both through the dependence on factor cost and shares, as well as through the (industry-specific) technical coefficients. For the purpose of this paper, it is not the elasticity of substitution that matters but $S^{I T} \sigma^{H, I T} \equiv$ $\eta^{I T}$ (see equation 6). This is the so-called cross-price elasticity, and it is independent from the ICT share in total production cost (not observed at the sector level). Economic theory further implies that the own-price elasticity of labour is $\eta^{H}=-\left(\eta^{I T}+\eta^{N I T}\right)$.

To capture lags in adjustment and to avoid the presence of a unit root, a dynamic version of equation 12 in differences is again adopted. Denoting the dependent variable $H / V A$ by $y$, and letting $r r p$ denote the respective roots of the relative cost terms:

$$
\Delta y_{t}=\sum_{s_{1}} \rho_{s_{1}} \Delta y_{t-s_{1}-1}+\sum_{s_{2}} a_{s_{2}}^{I T} \Delta r r p_{t-s_{2}}^{I T}+\sum_{s_{3}} a_{s_{3}}^{N I T} \Delta r r p_{t-s_{3}}^{N I T}+\varepsilon_{t} \quad s_{i}=0,1, \ldots(i=1,2,3)
$$

which is estimated for each of the sectors in our sample separately using the so-called System Generalized Method of Moments (SYS-GMM) estimator for dynamic panel data models suggested by Blundell and Bond (1998). This estimation method accounts for the endogeneity of the lagged dependent variable, as well as the potential endogeneity of the factor costs with respect to labour demand, which can arise because input costs and factor demand are determined simultaneously in the market. Not accounting for this endogeneity could lead to biased estimates of the regression coefficients. Using lags of the relevant variables, the GMM estimation procedure provides consistent estimates. ${ }^{8}$ 
The fact that the estimation controls for fixed effects makes the results robust to any time-invariant omitted variables or other specification and measurement errors. The specification further includes year dummies to control for possibly time-specific trends. Estimation by sector allows the technical coefficients to differ across industries, thus relaxing the assumption of a common production technology. In the context of this research, it is important to allow sectors to differ in their use of ICT, for instance.

Also the lag structure is allowed to differ by sector. The lags to include are determined based on significance and plausibility of the parameters, where $s_{i}$ ranges from 0 to 2 . As discussed in Blundell and Bond (1999), lags $t$-s of the independent variables in the equation can be used as instruments, where $s=2$ in the absence of measurement error, and $s=3$ otherwise. Exploratory estimations for the Manufacturing sector show that the diagnostics improve when $s=3$ rather than $s=2$. Hence, to be conservative with respect to the existence of measurement error, $s=3$ and higher lags are maintained as instruments in all sectors.

The long-run (sector-specific) coefficients needed for the calculation of the elasticities with respect to the cost of ICT are

$$
a^{I T}=\sum_{S_{2}} a_{S_{2}}^{I T} /\left[1-\sum_{S_{1}} \rho_{S_{1}}\right]
$$

e.g. when the dependent variable is lagged once, and the current and lagged relative cost of ICT are included, $a^{I T}=\left(a_{0}^{I T}+a_{1}^{I T}\right) /(1-\rho)$.

Different measures have been taken to avoid the influence of outliers. Firstly, value added, hours worked, and labour cost have been generically put to missing when the absolute relative change with respect to the previous year is more than $50 \%$. Moreover, observations where the dependent variable is negative or implausibly high are dropped. Finally, in each industry estimation the residual distribution was checked, and irregular observations were removed, where after the equations were re-estimated, iterating until no outliers were found.

The estimation results by sector are reported in Table A5. The diagnostic tests show that the instruments are valid except in two cases, where they are rejected only marginally (i.e. validity is rejected at the $5 \%$ significance level, but not at $1 \%$ ). The cross-price elasticities are depicted in Figure 10 of the main text, and use to derive the total effect in Figure 11. The implied wage elasticities seem to be plausible and in line with findings in the labour demand literature (e.g. Hamermesh, 1991, reports that the "overwhelming majority" of the literature reports estimates in the between -0.15 and -0.75 , and a "best guess" would be around -0.30 ). Interestingly, the results show that the wage elasticity varies across sectors. 
Table A5. Estimation results for labour demand equation by sector

\begin{tabular}{|c|c|c|c|c|c|c|c|c|c|c|c|c|c|c|c|c|}
\hline & $\mathrm{A}$ & & $\mathrm{B}, \mathrm{D}, \mathrm{E}$ & & $\mathrm{C}$ & & $\mathrm{F}$ & G-I & $\mathrm{J}$ & & $\mathrm{K}$ & & M-N & $\mathrm{O}-\mathrm{Q}$ & R-U & \\
\hline dependent variable (lag) & 0.786 & & 0.931 & 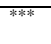 & 0.829 & (F+* & 0.882 & 0.777 & 1.085 & & 0.676 & & 1.071 & $1.043^{* * *}$ & 0.789 & \\
\hline dependent variable (second lag) & & & & & & & $-0.240^{* *}$ & & $-0.306 *$ & *** & & & $-0.207^{* * *}$ & $-0.214^{* * *}$ & & \\
\hline relative cost of ICT & 0.510 & ${ }^{* * *}$ & 0.508 & $* * *$ & 0.390 & ** & $0.412^{*}$ & $0.201^{*}$ & $0.652 *$ & *** & $0.235^{*}$ & * & $0.260^{* *}$ & $0.612^{* * *}$ & 0.667 & ${ }^{* * *}$ \\
\hline$-\operatorname{lag}$ & -0.458 & $* * *$ & -1.241 & $* * *$ & -0.289 & ${ }^{*}$ & $-0.384 *$ & $-0.345^{*}$ & -0.559 & *** & $-0.449^{*}$ & ** & $-0.204^{* *}$ & $-1.066^{* * *}$ & -0.858 & ${ }^{* * *}$ \\
\hline - second lag & & & 0.750 & *** & & & & 0.223 * & & & $0.294^{*}$ & *** & & $0.471^{* * *}$ & 0.201 & $*$ \\
\hline relative cost of non-ICT & & & & & & & $0.541^{* * *}$ & $0.180^{* *}$ & 0.323 & ** & $0.160^{*}$ & ** & 0.121 & & 0.135 & ** \\
\hline - lag & & & 0.499 & $* *$ & 0.206 & ${ }^{* * *}$ & $-0.587^{* * *}$ & -0.118 & $-0.696 *$ & *** & & & $-0.144^{*}$ & $0.135^{* * *}$ & & \\
\hline - second lag & & & -0.422 & $* * *$ & & & & & 0.439 * & *** & & & & $-0.053^{*}$ & & \\
\hline constant & 0.178 & ${ }^{* * *}$ & -0.040 & & -0.159 & $* * *$ & $0.420^{* * *}$ & 0.058 & 0.044 & & 0.032 & & 0.109 & 0.065 & 0.088 & \\
\hline Number of observations & 251 & & 182 & & 197 & & 202 & 203 & 202 & & 206 & & 193 & 202 & 193 & \\
\hline \multicolumn{17}{|l|}{ Significance of diagnostic tests at $5 \%$} \\
\hline Instruments valid (Sargan statistic) & yes & & yes & & yes & & no & no & yes & & yes & & yes & yes & yes & \\
\hline Second order AC (Arellano-Bond test) & no & & no & & no & & no & no & no & & no & & no & no & no & \\
\hline \multicolumn{17}{|l|}{ Long-run coefficients } \\
\hline ICT & 0.241 & & 0.253 & & 0.594 & ${ }^{* * *}$ & 0.058 & $0.353^{* * *}$ & $0.419^{*}$ & ** & $0.250^{*}$ & ** & $0.411^{* * *}$ & 0.099 & 0.041 & \\
\hline Non-ICT & & & 1.118 & & 1.207 & *** & $-0.026 *$ & 0.279 & 0.300 & & 0.494 * & ** & -0.173 & $0.479^{* *}$ & 0.636 & ** \\
\hline \multicolumn{17}{|l|}{ Cross-price elasticities (mean) } \\
\hline$\eta^{I T}$ & 0.147 & & 0.089 & & 0.263 & & 0.023 & 0.150 & 0.179 & & 0.084 & & 0.173 & 0.050 & 0.019 & \\
\hline$\eta^{N I T}$ & & & 0.407 & & 0.507 & & -0.010 & 0.115 & 0.119 & & 0.153 & & -0.072 & 0.234 & 0.294 & \\
\hline$\eta^{H}$ (implied) & -0.147 & & -0.495 & & -0.770 & & -0.013 & -0.267 & -0.298 & & -0.237 & & -0.102 & -0.283 & -0.313 & \\
\hline
\end{tabular}

,${ }^{* * * * *}$ means significant at $1 \%, 5 \%, 10 \%$ level.

Sector codes: A = Agriculture; B, D, E = Energy; C = Manufacturing; F = Construction; G-I = Trade, transport and accommodation; $\mathrm{J}=$ Information and Communication; $\mathrm{K}=$ Financial institutions; $\mathrm{M}-\mathrm{N}=$ Business services; O-Q = Government and care; R-U = Culture, recreation and other services.

Results for agriculture exclude self-employment.

Estimation method is SYS-GMM (Blundell and Bond, 1998) using lags t-3 and further back as instruments. All regressions include year dummies 


\section{Estimation of the output demand elasticities (demand effect) and export elasticities}

The effect of a price change on output demand consists of a price effect an income effect. In turn, the price effect is a weighted average of the elasticity of both domestic and foreign demand (exports). The price and income effect can be obtained conveniently through the (QU)AIDS method, see Deaton and Muellbauer (1981) and Banks et al. (1997). While the methodology is designed to model consumer demand for specific products in the face of changes in prices and/or income, it is possible to apply the same logic to the aggregate demand for industry output by regarding total economy value added as 'total income', defining shares in output as 'expenditure shares', and using output deflators to measure changes in prices.

To obtain meaningful estimates for the demand and income elasticities, one needs to take into account substitution of domestically produced goods and services for imports. While data on import and export values are readily available, deflators are not. Therefore, import deflators have to be derived.

It is assumed that for each sector, domestic consumption of country $i$ is a CES (constant elasticity of substitution) aggregator of domestic $(h)$ and foreign produced $(f)$ goods and services of the form:

$$
C_{i t}=\left\lfloor a^{\frac{1}{d}} C_{i h t}^{\frac{d-1}{d}}+(1-a)^{\frac{1}{d}} C_{i f t}^{\frac{d-1}{d}}\right\rfloor^{\frac{d}{1-d}}
$$

Standard optimization leads to the demand functions. Taking the ratio,

$$
C_{i h t} / C_{i f t}=\frac{a}{1-a}\left(\frac{P_{i h t}}{P_{i f t}}\right)^{-d}
$$

Taking logs,

$$
\ln \left(\frac{C_{i h t}}{C_{i f t}}\right)=\ln \left(\frac{a}{1-a}\right)-d \ln \left(P_{i h t}\right)+d \ln \left(P_{i f t}\right)
$$

The problem is that we do not observe $P_{i f t}$. It is assumed that the import price faced by country $i$ can be approximated by an exponential function of the average output price of all other trade partners:

$$
P_{i f t} \approx \bar{P}_{h t}^{m_{i}}
$$

where $m_{i}$ is a country-specific dummy variable. Inserting this in the equation,

$$
\ln \left(\frac{C_{i h t}}{C_{i f t}}\right)=\ln \left(\frac{a}{1-a}\right)-d \ln \left(P_{i h t}\right)+d\left[m_{i} \times \ln \left(\bar{P}_{f t}\right)\right]+\varepsilon_{i t}
$$

This equation is easily estimated with constrained OLS and adding time dummies. After having estimated all country-specific dummies, $\left\{\widehat{m}_{i}\right\}$, one can obtain $\widehat{P_{\text {lft }}}$.

The composite price index is given by

$$
P_{i t}=\left[a P_{i h t}^{1-d}+(1-a) P_{i f t}^{1-d}\right]^{\frac{1}{1-d}}
$$


With this information, import and domestic demand are added to compute expenditure shares. Together with the above price index, the elasticities are estimated using QUAIDS.

To obtain the export elasticities, the following equation is estimated with OLS

$$
\ln \left(X_{c s t}\right)=\beta_{0}+\beta_{1} \ln \left(Y_{c s t}\right)+\sum_{s=1}^{s} \beta_{2 s} \ln \left(\frac{P_{c s t}}{P_{s t}^{w}}\right) d_{s}+d_{t}+u_{c s}+\varepsilon_{c s t}
$$

where $X_{c s t}$ is real export, $Y_{c s t}$ nominal GDP to control for demand effects, $P_{c s t}$ is export price, $P_{s t}^{w}$ is a world export-price deflator, $d_{s}$ is a sector dummy, $d_{t}$ year dummy, and $u_{c s}$ is a country-sector fixed effect.

Errors are clustered at the sector level, meaning that errors are allowed to be correlated across countries within the same sector. The world export price deflator is an export-weighted average of producer prices of all countries in the sample.

The income elasticities and the price elasticity of both domestic demand and exports are shown in Figures 10a to 10c of the main text. They are further used, together with the substitution effect, in the calculation of the overall effects shown in Figure 11. 


\section{ANNEX NOTES}

This prediction is confirmed in our dataset by hypothesis testing based on a cluster-robust GLS estimation.

Notice that the share equation of ICT capital summarizes all the information we seek on each category of labour.

Thus, the parameters must satisfy the restriction $b_{i j}^{1}=-b_{i j}^{0}(1+\rho)$ and $b_{i j}^{2}=b_{i j}^{0} \rho$.

The SURE method essentially consists in a GLS which take into account potential cross correlation of the errors, improving the efficiency of the estimates.

Of course, solving a system of equation including labour demand as well as labour supply would be the most rigorous exercise. However, this goes beyond the analysis in the current paper, and it is left as a task for future research.

However, although the estimation of both the substitution and the demand parameters is not affected, , assumptions about the cost share of ICT have to be made to derive the overall effect in (1).

As discussed for the analyses by skill-level, the labour demand equation is part of a system of factor demand equations, together with the equations for ICT and non-ICT capital. Due to the lack of data on capital services by sector, it is not possible to estimate the whole system of simultaneous equations. This leads to a loss of efficiency in the estimates, but the results are still unbiased.

Note that the qualification System estimator refers to the fact that the estimator considers both the estimating equation in levels as well as the differenced equation, and does not concern the system of factor demand equations. 